University of Louisville

ThinkIR: The University of Louisville's Institutional Repository

Electronic Theses and Dissertations

$5-2021$

\title{
A qualitative look at secondary trauma through the lived experiences of elementary teachers.
}

Terri L Davenport

University of Louisville

Follow this and additional works at: https://ir.library.louisville.edu/etd

Part of the Education Commons

\section{Recommended Citation}

Davenport, Terri L, "A qualitative look at secondary trauma through the lived experiences of elementary teachers." (2021). Electronic Theses and Dissertations. Paper 3657.

https://doi.org/10.18297/etd/3657

This Doctoral Dissertation is brought to you for free and open access by ThinkIR: The University of Louisville's Institutional Repository. It has been accepted for inclusion in Electronic Theses and Dissertations by an authorized administrator of ThinkIR: The University of Louisville's Institutional Repository. This title appears here courtesy of the author, who has retained all other copyrights. For more information, please contact thinkir@louisville.edu. 


\title{
A QUALITATIVE LOOK AT SECONDARY TRAUMA THROUGH THE LIVED EXPERIENCES OF ELEMENTARY TEACHERS
}

\author{
By \\ Terri L. Davenport \\ B.A., University of Louisville, 1997 \\ M.Ed., University of Louisville, 2002

\begin{abstract}
A Dissertation
Submitted to the Faculty of the

College of Education and Human Development of the University of Louisville in Partial Fulfillment of the Requirements

for the Degree of
\end{abstract} \\ Doctor of Education \\ In Educational Leadership and Organizational Leadership \\ Department of Educational Leadership, Evaluation, \& Organizational Development \\ University of Louisville \\ Louisville, Kentucky
}

May 2021 


\section{Copyright 2021 by Terri Davenport}

All rights reserved 

A QUALITATIVE LOOK AT SECONDARY TRAUMA THROUGH THE LIVED EXPERIENCES OF ELEMENTARY TEACHERS

\author{
By \\ Terri L. Davenport \\ B.A., University of Louisville, 1997 \\ M.Ed., University of Louisville, 2002 \\ A Dissertation Approved on
}

April 21, 2021

by the following Dissertation Committee:

Dr. Mary Brydon-Miller

Dr. Meera Alagaraja

Dr. Harrie Buecker

Dr. LaMesa Marks-Johns 


\section{ACKNOWLEDGEMENTS}

I give all the honor and praise to my Lord and Savior for allowing me to see this process through to completion. On my orientation day into the doctoral program, one of the advisors declared that life would continue to happen while you are making your way along. Indeed, it has! The journey has been long, uphill, and deep down in the valley. God's peaceful reminder that he is still with me afforded me the conviction to get through. I am grateful that he provided me with my wonderful husband, Nelson, who helped me to keep my eye on the prize. He has been my cheerleader and provider during difficult days when quitting seemed to be the logical road to take in response to illness and other challenges that invaded our space. Thanks to the rest of my family for graciously accepting my apologies when I turned down their requests to engage because my energies were spent on completing my study.

I want to thank my chair, Dr. Mary Brydon-Miller, for her patience and encouragement through this entire process. Thank you for seeing the potential in my ability to do this work and the grace you extended to me when personal trials prioritized my time. I would also like to thank Dr. Meera Alagaraja, Dr. Harrie Buecker, and Dr. LaMesa Marks-Johns for their expertise and guidance as members of my dissertation committee.

Special thanks to my accountability partner Tonya Holt. We have spent countless hours together at Panera, in the library, and even virtually. Your love and support have played a tremendous role in getting me closer to the goal. Please know that I 
will continue to be a steadfast to you throughout the completion of your study as well. I am also grateful for the members of my university cohort and other students that willfully shared ideas and tips for completing the various stages of dissertation work. Finally, I would like to acknowledge educators everywhere and the difficult balance they have of supporting students while protecting their own well-being. I hope this work will illuminate those challenges and create opportunities to care for those that are caring for children - our future. 


\section{ABSTRACT \\ A QUALITATIVE LOOK AT SECONDARY TRAUMA THROUGH THE LIVED EXPERIENCES OF ELEMENTARY TEACHERS}

Terri L. Davenport

April 3, 2021

This research study examined the lived experiences of elementary educators working with traumatized students. Secondary trauma among other professions such as social workers and first responders is well-documented (Bride et al., 2007). Research on the impact it has on educators is still limited (Hill, 2011). This dissertation provides evidence that educators are directly impacted by the work that they do to support and educate their students.

A phenomenological approach is used to explore the troubling personal challenges educators face while working with traumatized students. The study examines elementary teachers' experiences using the Secondary Traumatic Stress (STS) lens as a theoretical framework. It opens with the sobering reality of urban school settings and the significant number of students exposed to trauma. An in-depth look at the various secondary trauma constructs is presented, along with an examination of protective factors that can be implemented. The study also illustrates the types of trauma experienced by children and the challenges it presents to educators providing support to students. The findings present compelling evidence that educators experience distressing emotions, intrusive imagery, physiological arousal, and other indicators aligned to STS. 
The study exposes the importance of applying STS to the education occupation and explores preventative self-care responses to deflect the harming effects on those who are committed to serving others. 


\section{TABLE OF CONTENTS}

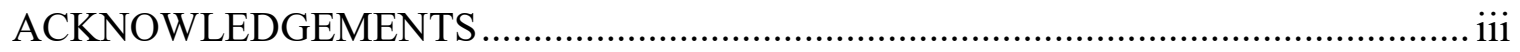

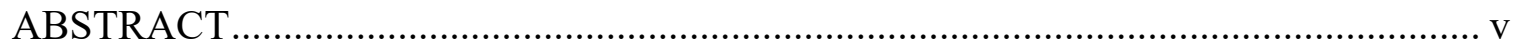

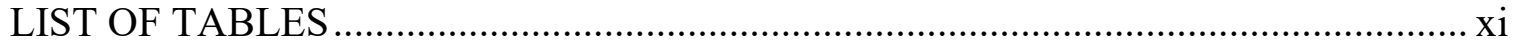

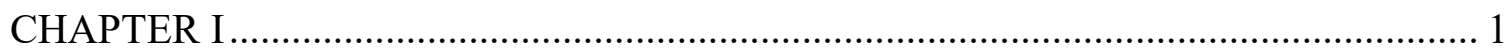

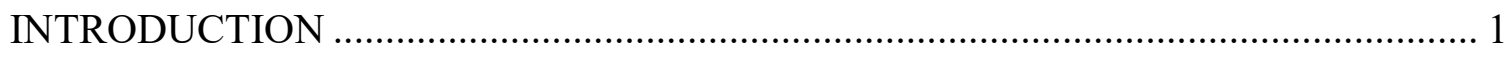

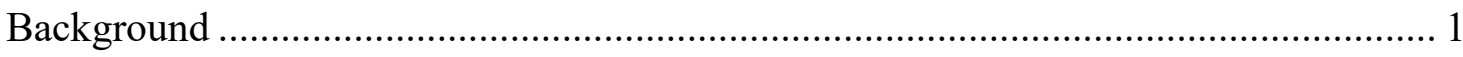

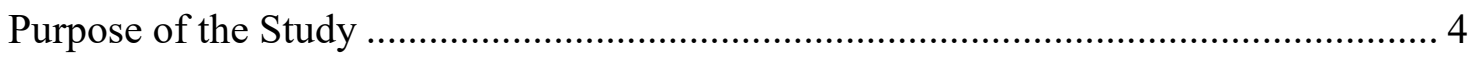

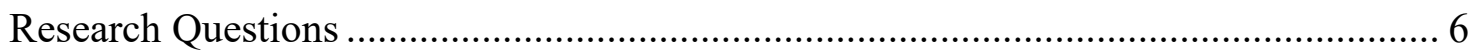

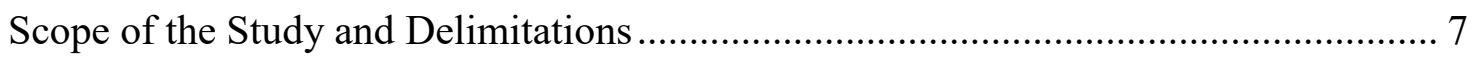

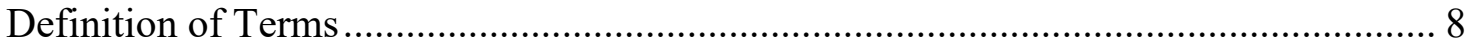

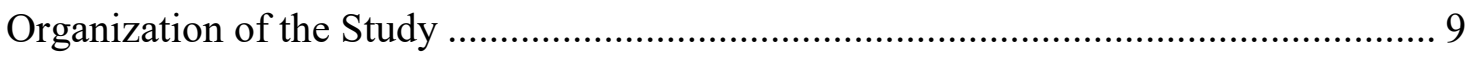

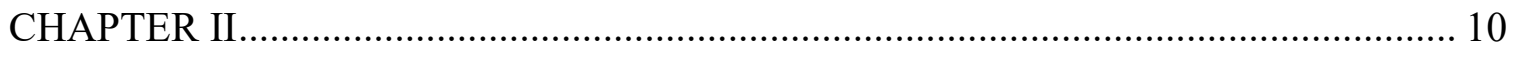

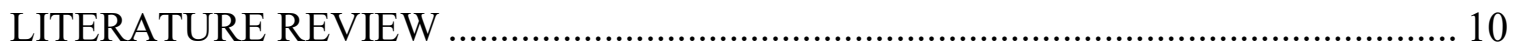

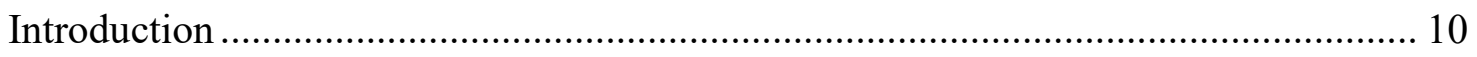

Secondary Trauma in the Helping Profession..................................................... 11

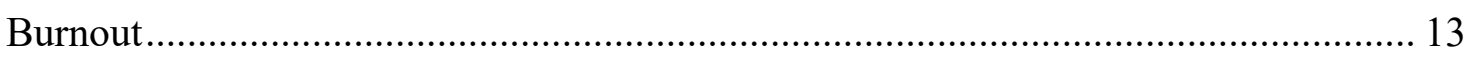

Compassion Fatigue and Vicarious Trauma ....................................................... 14

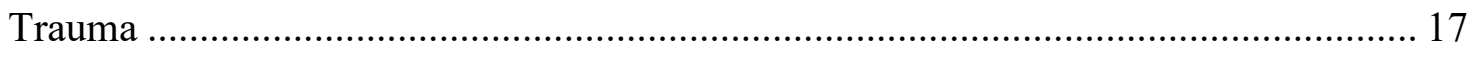

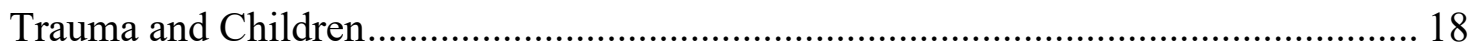

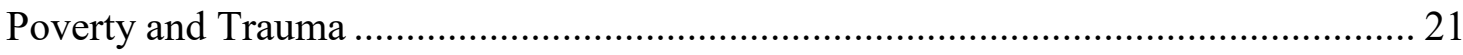

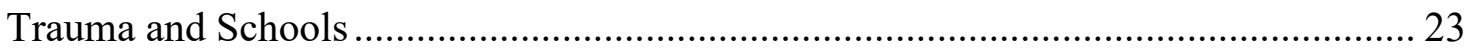


Schools as Mental Health Facilitators .................................................................. 25

Secondary Traumatic Stress Among Urban School Educators ................................... 26

Self-Care

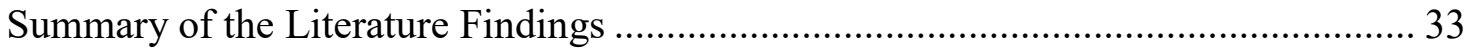

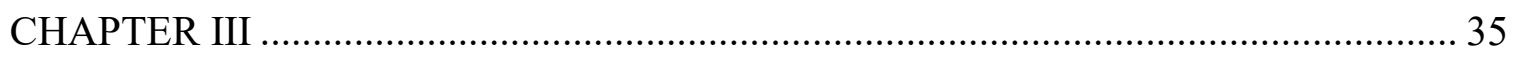

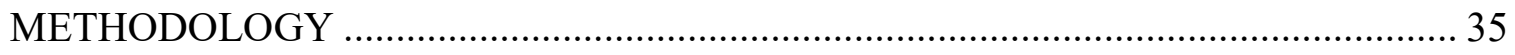

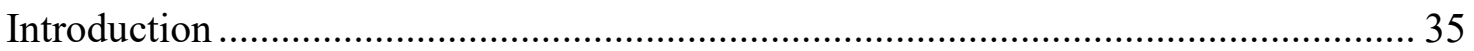

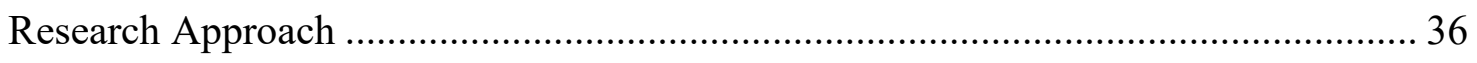

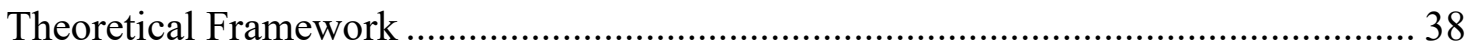

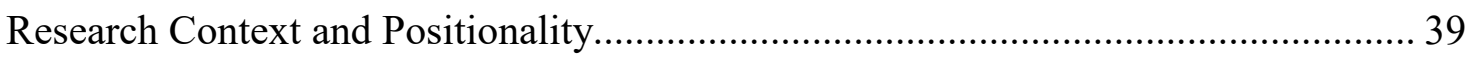

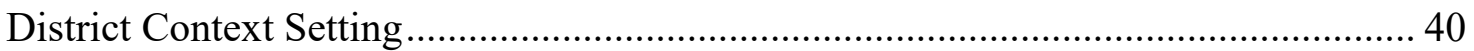

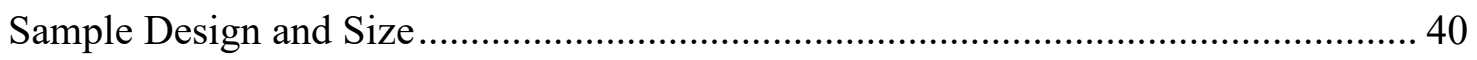

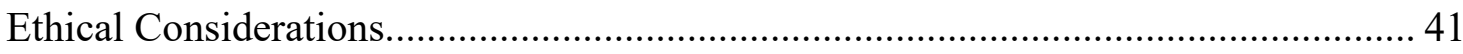

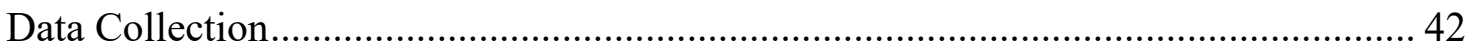

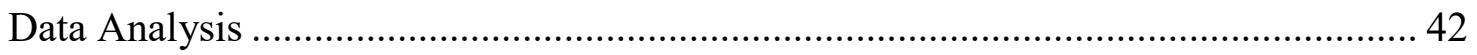

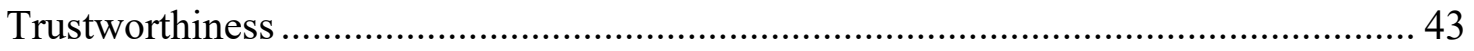

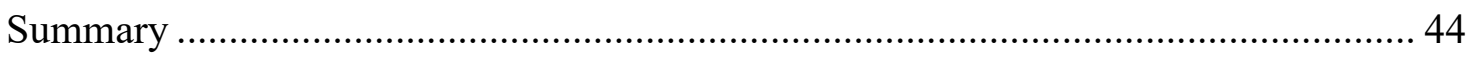

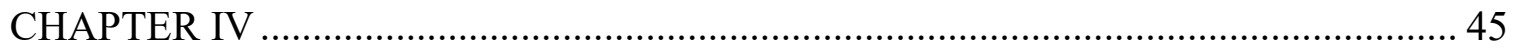

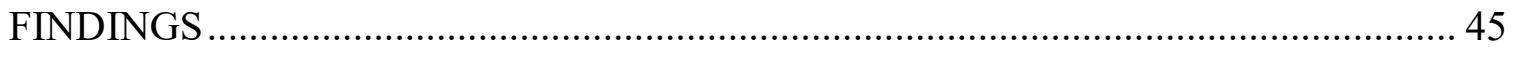

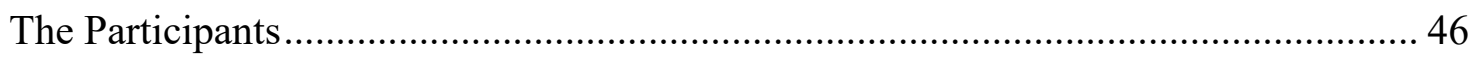

Traumatic Events Experienced by Students .............................................................. 47

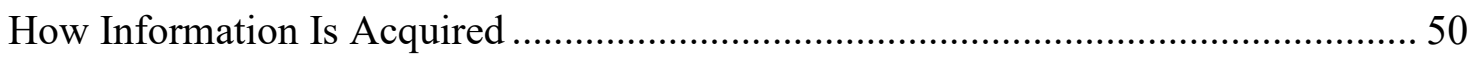

Personal Impact of Working with Students Exposed to Trauma ................................... 54 
Distressing Emotions and Intrusive Imagery .................................................. 56

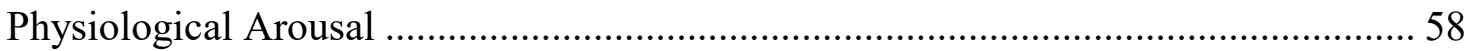

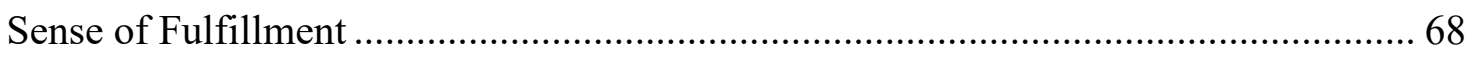

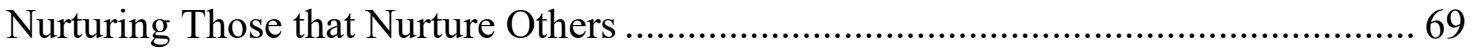

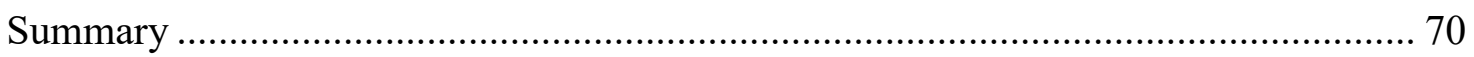

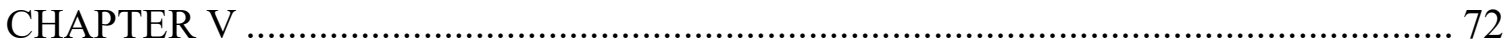

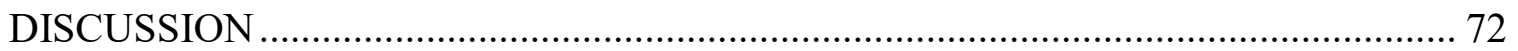

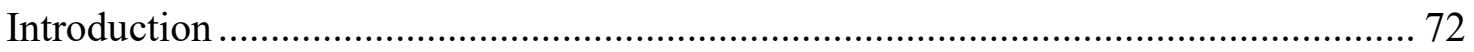

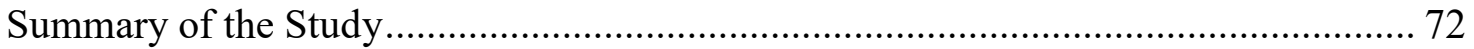

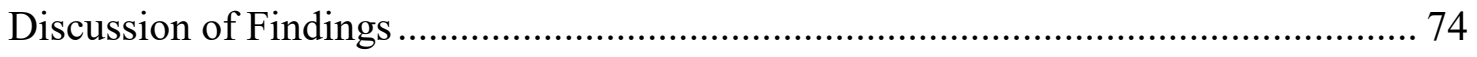

Distressing Emotions and Intrusive Imagery .................................................... 76

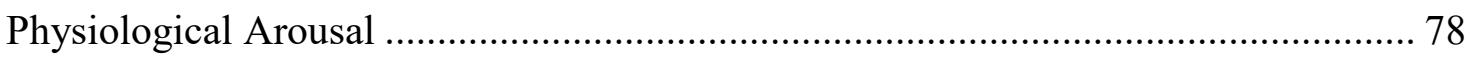

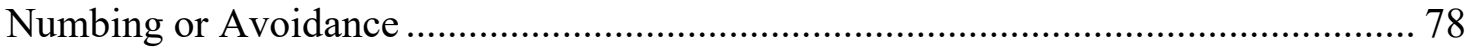

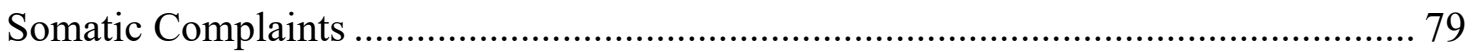

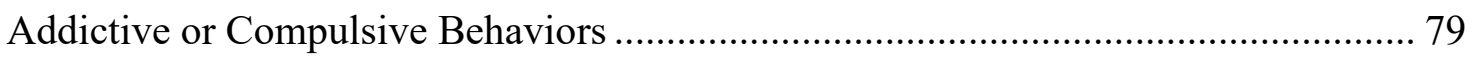

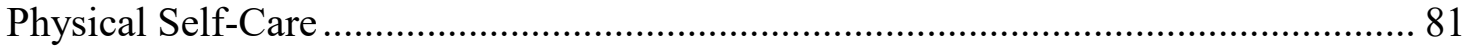

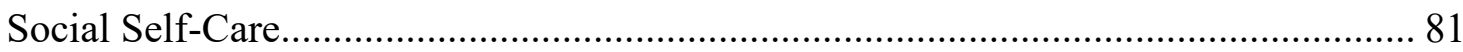

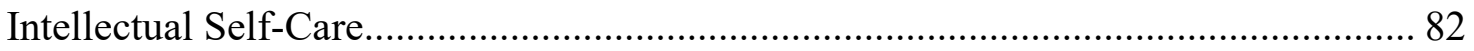

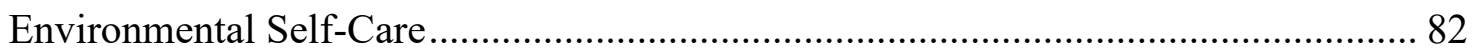

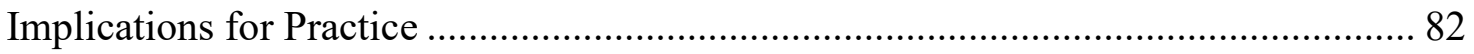

Recommendations for Future Research ............................................................ 86

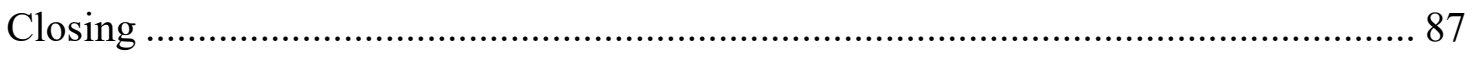

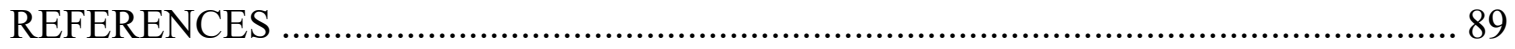




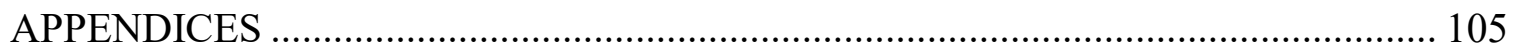

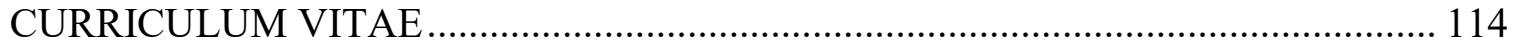




\section{LIST OF TABLES}

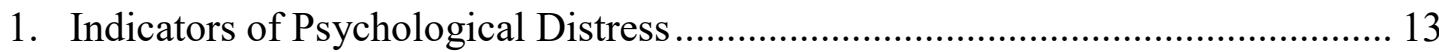

2. Comparison of Burnout, Vicarious Trauma, and Secondary Traumatic Stress .... 16

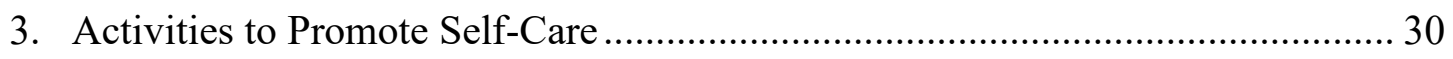

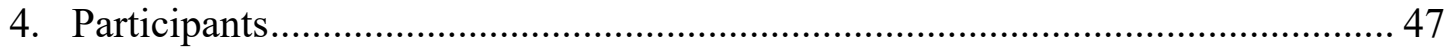

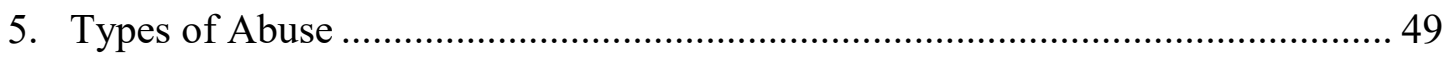

6. Indicators of Psychological Distress or Dysfunction............................................ 55 


\section{CHAPTER I}

INTRODUCTION

\section{Background}

Olsen (2008) surveyed teachers and found that providing a public service was a significant motivator for entering the teaching field. This desire to see students succeed is a rewarding factor despite the stress teachers often face (Swathi \& Reddy, 2016). There are varying demands that teachers are expected to meet to provide students with the knowledge and skills necessary to succeed in society (Darling-Hammond, 2006). Educators are required to ensure that children are able to obtain an education regardless of the student's socioeconomic status, academic ability, and parental involvement.

One significant challenge to educators is that increasingly more students are arriving at the schoolhouse door with the scars and baggage of trauma. The number of children who experience trauma and the potential consequences is alarming and is both a social and public health challenge (Yehuda, Halligan \& Grossman, 2011). According to

the National Center for Mental Health Promotion and Youth Violence Prevention (2012), $26 \%$ of children in the United States will witness a violent act or directly experience a traumatic event before they turn 4.

Trauma is defined by the American Psychiatric Association (2013) as experiencing a direct personal event that threatens death or serious injury, witnessing an event that involves those acts, or learning of such an event happening to a family member 
or loved one. According to a national study, nearly half of all children in the United States have experienced serious trauma (Child and Adult Adolescent Health Measurement Initiative, 2013). Adverse childhood experiences include physical, sexual, or emotional abuse, divorce or separation, domestic violence toward a parent, addictions, and parental separation due to divorce, separation, or incarceration (Felitti et al., 1998). Children who are repeatedly exposed to traumatic events can have impairments in their ability to interact with others, including teachers and peers (Ko et al., 2008). They may exhibit reactional behaviors that cause harm to themselves and others.

As the number of students entering the classroom with these experiences rises, we must ask how prepared teachers are to meet the needs of students who have experienced trauma. Teachers typically receive little formal training or professional development on the impact of trauma on students and ways they can help traumatized students achieve better educational outcomes (Alisic et al., 2012; Ko et al., 2008). Learning about a crisis or ongoing trauma of their students or managing the behavioral demands of these students can cause emotional distress that may impair the educator's functioning (Hydon, Wong, Langley, Stein \& Kataoka, 2015). Those charged with providing care for children exposed to such disturbances are subject to secondary traumatic stress (STS) as a result of that response. It has been said that you must have the heart for teaching. More specifically, you must have a caring heart. What is the cost for that caring heart? The natural consequence of a caring heart can oftentimes lead to what is known as secondary trauma (Figley, 1995).

Often, educators can readily recount experiences of working with traumatized students. Educators working in urban schools with a significant population of African 
American students who qualify for free and reduced meals have a greater likelihood of working with students exposed to trauma (Crouch, Hanson, Saunders, Kilpatrick, \& Resnick, 2000). Teachers in these settings can find these experiences to be common and are likely to share multiple stories of their interactions due to the larger volume of students who have experienced trauma.

Elementary teachers, in particular, spend a lot of time with their students, as they rarely move from one teacher to another during the day, like middle and high school students. Teachers in these settings are more likely to learn of their students' experiences as well as the behaviors they manifest as a result. Learning of students' exposure to abuse and neglect, abandonment, and rejection, as well as violence in the community on a regular basis, has the potential to impose secondary traumatic stress on school educators. The educators may need support in identifying and responding to the emotional and physical changes that manifest in themselves as a response to exposure to their students' experiences.

Dutton and Rubinstein (1995) identify the following indicators of secondary traumatic stress (p. 85):

- Distressing emotions

- Intrusive imagery

- Numbing

- Somatic complaints

- Addictive or compulsive behaviors

- Physiological arousal

- Impairment of day-to-day functioning 
Over time, the emotional and physical toll of operating in this space can consume those in professions charged to help others. As the helper, educators may begin to feel frustration, exhaustion, or burnout resulting from supporting students who have negative or challenging survival strategies in response to trauma (Valent, 1995).

\section{Purpose of the Study}

In the fall of 2010, I experienced an event that rocked the very core of my being and forced me to feel the pain and suffering of a student in my care. Larry (pseudonym) was distraught early in the day. He was typically a challenging student who often thrived on being the center of attention by distracting classmates and making fun of his fifthgrade peers. Because of his reputation for being a bully, many students chose to establish an alliance with him rather than being the butt of his antics. However, on this day, Larry arrived at the school extremely agitated.

As the school principal, I wanted to get to the root of what was bothering Larry. I invited him to my office for what I thought would be a brief dialogue. To my astonishment, Larry sunk into a chair and almost immediately began to sob. Over the next half hour, he shared with me the events of the previous evening. His mother was a recovering drug addict who had occasional visits with her son, which sometimes included overnight stays. Larry shared that his mother and her boyfriend picked him up at his grandmother's house, and almost instantly, they begin arguing. He stated that before they arrived at his mother's home, the boyfriend had already punched him twice and screamed obscenities. The beating continued once they got inside.

On this day, Larry, the fifth-grade bully, was scared. After reassuring him that I would ensure he was safe and convincing him to return to class, I began making the 
necessary calls to child protective services and following other administrative procedures. Hours went by, and there was no response. As the school day crept closer to an end, I began to become distressed, worried that I would not be able to keep my promise. After several attempts to reach Larry's grandmother, I had to decide to either risk putting him on the bus and potentially exposing him to additional harm by his mother or keep him at the school. I decided against sending him home and prayed that his grandmother would arrive and I could release him in her care.

Instead, Larry's mother arrived irately and demanded that I release him. I shared my concerns and suggested that since the grandmother had custody, that we would release him once she was reached. By this time, the mother was furious, and I called the local authorities to allow them to help sort things out. The police arrived and questioned Larry about the previous evening. Again, Larry sobbed and shared that he did not want to go with his mother. The next event continues to haunt me to this day. The officers convinced Larry that they had spoken to his mother, and she acknowledged the previous night had just gotten out of hand, and he would be safe. The officer's parting words, "If something happens, tell someone," was more than I could bear. I watched in horror as a dejected Larry walked out the door. All day, I was the person whom he told something was going to happen to him. I walked away, visibly upset, and found myself in the throes of uncontrollable crying on the way home. That night I laid awake worried about Larry.

Experiences such as this one were a regular occurrence during my tenure as principal. Day in and day out, I put my heart and soul into my work, including sometimes following up on the weekends with children and their families whom I was particularly concerned about. By my third year, I began to experience an overwhelming emotional 
state that I could not shake. It began to take a physical toll that included restless nights and anxiety. My weight escalated out of control, and ultimately I started losing my hair. When my doctor suggested medication, I was certain that my work experiences were having a devastating influence on me.

Daily, teachers face the challenge of raising academic achievement while navigating some of the complexities children are facing. The stress on teachers can be

overwhelming. More recently, research has suggested that educators suffer from the same phenomena of STS as others in the caring professions (Hydon et al., 2015). Yet little movement has occurred in providing training tools and awareness to those who work with traumatized students. Hill (2011) suggests that further research on teachers in urban elementary schools be conducted to see if the teachers' symptoms are consistent with the finding of studies regarding other occupations.

\section{Research Questions}

In this qualitative study, I explored secondary trauma among educators. I posed the following research questions:

1) How do educators acquire information about their students' traumatic experiences?

2) How do the lived experiences of elementary teachers working with students who have been exposed to trauma influence the educator?

3) How do teachers cope with and process their experiences of working with traumatized students?

The goal of these questions was to gain insight from educators on how they have been impacted by their students' emotional pain and the coping mechanisms they used to 
manage the experiences. By providing research on this topic, I hope to advance the education community by bringing an awareness of the emotional and physical toll secondary trauma can place on educators. Early detection and coping strategies are identified that may yield positive influences on the well-being of educators. This awareness and intervention could have made a difference for me as principal.

\section{Scope of the Study and Delimitations}

This research study utilized a phenomenological research design. Creswell (2014) identifies phenomenological research as a design of inquiry derived from philosophy and psychology in which the researcher describes the lived experiences of individuals and then maps a phenomenon as described by the participants. I used semi-structured interviews with participants. This interview technique allows for a set of interview questions, while allowing questions to be reformed and additional questions added throughout the research process and impromptu in-depth probes to allow the participants to tell their stories (Glesne, 2016). This allowed me to follow the participant through the experiences they shared in an effort to best capture the exposure and strategies they used to cope.

A purposive sampling strategy was employed in this study. Nonprobability sampling is a research technique that allows samples to be gathered in a process that does not give all the participants in a given population equal chances of being included (Etikan, Musa, and Alkassim, 2016). This study's sample target was educators working in elementary schools with a high population of students who qualify for free and reduced meals. Teachers in schools who did not meet this criteria were excluded from participating in the study. 


\section{Definition of Terms}

The following terms are used in this study:

Compassion Fatigue: The adverse effects of emotional and physical fatigue that any professional experiences due to the chronic encounters of individuals who have experienced extreme emotional pain or trauma over a period of time (Figley, 1995)

Post-Traumatic Stress Disorder: A debilitating mental health condition that emerges following a psychologically stressing event (American Psychiatric Association [APA], 2013; National Child Traumatic Stress Network [NCTSN], 2016)

Secondary Trauma/Secondary Traumatic Stress: The natural consequent behaviors and emotions resulting from knowledge about a traumatizing event experienced by a significant other. The stress resulting from helping or wanting to help a traumatized or suffering person can be immediate, occurring after one experience (Figley, 1995)

Self-care: Activities performed with the intention of improving or restoring health and well-being (Strömberg, Jaarsma, \& Riegel, 2012)

Trauma: The emotional and physical impact after exposure to frightening, often dangerous or violent events or conditions that are experienced as overwhelming (APA, 2013; NCTSN, 2016)

Vicarious Trauma: Cumulative transformative effect on individuals working with survivors of traumatic life events that alters thinking or distortions in beliefs (Pearlman \& Mac Ian, 1995).

The symptoms of secondary trauma and other constructs such as burnout, compassion fatigue, and vicarious trauma are very similar. The opinions vary among 
researchers on considering the terms interchangeably. Pearlman (Wilcox, 2001) argues that these are different phenomena with different origins and manifestations. I chose to use secondary traumatic stress because of the immediate impact symptoms can manifest in the sufferer. In addition, secondary traumatic stress implies that the victim's initial trauma has influenced the person wishing to help. Educators are poised in the work they do with students to be impacted by this phenomenon.

\section{Organization of the Study}

This study is organized as follows: Chapter I includes the background, purpose of the study, scope of the study, key terms, and research questions. Chapter II reviews the literature on childhood trauma, the presence of trauma in schools, and the impact of secondary traumatic stress on educators. Chapter II also discusses the gap in training to support educators and to promote awareness of secondary trauma and support for the educators' well-being. Chapter III presents an explanation of the research design and method, data collection, and analysis. Chapter IV presents a descriptive narrative of the findings from the data analysis. Chapter V summarizes the significant findings and implications for practice and closes with recommendations for future research. 


\section{CHAPTER II}

\section{LITERATURE REVIEW}

\section{Introduction}

The purpose of this study was to examine how STS influences educators working with students who have experienced trauma. Exposure to their students' experiences can have a debilitating effect on educators. A modest search will yield substantial evidence of secondary trauma's risk on those exposed to the traumatic experience(s) of the individuals they serve. Empirical studies on secondary trauma regularly cite first responders, social workers, and therapists (Bride, 2007; Figley 1995; Jankoski, 2010). However, very little research has included educators in the populations impacted by this phenomenon (Hydon et al., 2015). Teachers are on the frontlines each day in classrooms. They are faced with emotional battles that many of their students have yet to develop coping mechanisms to manage. The day-to-day interactions can have a devastating impact on the educator and potentially influence them outside of the classroom walls. This study will expose the experiences of educators and promote awareness and intervention of STS.

This chapter will establish the conceptual framework for this study by defining secondary traumatic stress and similar constructs such as vicarious trauma and compassion fatigue. 


\section{Secondary Trauma in the Helping Profession}

The helping profession is described as occupations in fields that include psychology, counseling, medicine, social work, and education (APA, 2020). Those in helping professions are often exposed to trauma imagery repeatedly as they attempt to support the individuals they serve (Bride, 2007). According to McCann and Pearlman (1990), the exposure can manifest into symptoms similar to patients who have posttraumatic stress disorder (PTSD), listed in The Diagnostic and Statistical Manual of Mental Disorders (5 $5^{\text {th }}$ ed.). (American Psychiatric Association, 2013). These symptoms include disturbing thoughts, feelings, or dreams related to a traumatic event or experience (APA, 2013). Secondary trauma also disturbs the helper's ability to think clearly and process emotions (Geller, Madsen \& Ohrenstein, 2004).

Certain conditions can be considered high risk for those working with individuals who have experienced trauma (Pearlman \& Saakvitne, 1995). Those professions that involve individuals sharing details about traumatic experiences are at very high risk for STS. When those events also include emotional and physical responses from the persons, the STS can be overwhelming for those choosing to care for these victims.

Over the years, several studies have researched the impact of STS (Bride, 2007). A number of labels have emerged for the phenomenon. They include secondary traumatic stress, compassion fatigue, and vicarious trauma. Charles Figley (1995) coined the name STS as the natural consequent behaviors resulting from knowledge about a traumatizing event experienced by a significant other. It is the stress resulting from wanting to help a traumatized or suffering person. Figley (1995) expands the definition by acknowledging that STS can occur from the stress of wanting to help a traumatized or 
suffering person. STS is a natural response to working with individuals who have experienced trauma (Yassen, 1995).

The impact of secondary trauma can be immediate. Professionals working closely with trauma survivors become indirect victims of trauma through secondary traumatic stress. Educators who learn of their students' experiences, or those exposed to the behavior responses from these children, can have an adverse reaction and become impaired due to the trauma that has been revealed (Figley, 1995). Educators' natural desire to care for their students becomes the conduit for secondary trauma. A number of constructs have been used to identify the impact this has on those working with traumatized individuals. The concepts include burnout, secondary traumatic stress, compassion fatigue, and vicarious trauma.

Dutton and Rubinstein (1995) categorize the reactions professionals may face in their work with those exposed to trauma. They identify seven indicators of psychological distress or dysfunction. Table 1 illustrates STS characteristics and how it is manifested (Dutton \& Rubinstein, 1995, p. 85). 


\section{Table 1}

Indicators of Psychological Distress

\begin{tabular}{ll}
\hline Indicators of STS & Symptoms of STS \\
\hline Distressing emotions & $\begin{array}{l}\text { Sadness, grief, depression, anxiety, dread, horror, } \\
\text { fear, rage, shame }\end{array}$ \\
\hline Intrusive imagery & $\begin{array}{l}\text { Nightmares, flooding, and flashbacks of images } \\
\text { generated during and following the client's recounting } \\
\text { of traumatic events }\end{array}$ \\
\hline Numbing or avoidance & Avoidance of things that serve as reminders of work \\
\hline Somatic complaints & $\begin{array}{l}\text { Sleep difficulty, headaches, } \\
\text { gastrointestinal distress, heart palpitations }\end{array}$ \\
\hline Addictive or compulsive behaviors & $\begin{array}{l}\text { Substance abuse, workaholism, compulsive eating } \\
\text { Physiological arousal }\end{array}$ \\
\hline Impairment of day-to-day functioning & $\begin{array}{l}\text { Absenteeism, chronic lateness, poor work } \\
\text { performance, quitting a job, decreased ability to } \\
\text { engage in self-care behaviors, feelings of isolation, } \\
\text { alienation }\end{array}$ \\
\hline
\end{tabular}

\section{Burnout}

Burnout is an established construct with empirical research studies since the 1970s (Devilly, Wright \& Varker, 2009). Burnout is described as "a psychological syndrome of emotional exhaustion, depersonalization, and reduced personal accomplishment that can occur among individuals who work with other people in some capacity" (Maslach, Jackson, \& Leiter, 1998, p. 192). Numerous studies have identified high levels of stress as a contributing factor to burnout (Etzion, 1984; Maslach, Schaufeli, \& Leiter, 2001; McManus, Winder, \& Gordon, 2002). Specifically, job burnout has emerged as a significant workplace factor. Early studies focused on what was described 
as burnout to define the psychological strains for frontline workers providing services to victims of trauma (Freudenberger \& Robbins, 1979; Pines \& Maslach, 1978).

Burnout manifests as depression, loss of compassion, or cynicism (Freudenberger \& Robbins, 1979). The worker suffering from burnout may exhibit physical symptoms such as headaches and sleeplessness (Pines \& Maslach, 1978). Ultimately, the employee experiencing burnout may no longer have the capacity to make a meaningful contribution to the work they are expected to perform (Schaufeli, Leiter, \& Maslach, 2009).

While there are similarities in burnout and STS, there is a significant difference: Secondary trauma can be immediate and overwhelmingly powerful, while burnout emerges over time (Freudenberger \& Robbins, 1979). Those seeking refuge from burnout can leave their careers, and the phenomenon stops (Best Start Resource Centre, 2012), while victims suffering from secondary traumatic stress have lingering effects that go beyond the work environment.

\section{Compassion Fatigue and Vicarious Trauma}

Compassion fatigue was identified by Figley (1995) as a substitute term for secondary traumatic stress. This was due in part to earlier research into secondary trauma that recognized nurses found the term to be less derogatory. Figley (1995) writes,

"feeling the stress and even fatigue, of compassion in the line of duty, better describes the causes and manifestations of the duty-related experiences" (p. 15). Figley (1995) defines compassion fatigue as "a state of exhaustion and dysfunction — biologically, psychologically, and socially — as a result of prolonged exposure to compassion stress and all that it evokes" (p. 253).

There is an inherent risk to those in the helping profession. That risk is repeated 
exposure to learning of traumatic experiences of those they serve. This is known as the cost of caring. Educators, by nature, are expected to have a caring heart and respond to the needs of their students. The energy exerted to meet that need can be emotionally demanding. This can be quite overwhelming for the educator. Compassion stress can easily take over and lead to compassion fatigue. When this happens, the "helper" may become disengaged as compassion fatigue sets in. This can ultimately cause harm to not only the helper but the people they serve as well.

McCann and Pearlman (1990) first used the name vicarious trauma (VT) to define the changes in a counselor or therapist's capacity to think clearly and process emotions. VT has been characterized as:

...strong reactions of grief, rage, outrage, which grows as we hear about and see people's pain and loss and are forced to recognize human potential for cruelty and indifference, it is our numbing, our protective shell, and our wish not to know which follow those reactions" (Saakvitine, Pearlman, \& Abrahamson, 1996, p. $41)$.

VT is grounded in the constructivists self-development theory (CSDT). CDST is a comprehensive personality theory that illustrates the impact of trauma on the development of self (McAnn.\& Pearlman, 1992). CSDT attempts to discover why traumatic events have a significant impact on some, while others have the ability to move past the experience with minimal influence on their life. The basis for the theory exists using the constructivist assumption that individuals construct and construe their own realities (Epstein, 1985). Disruptions to those realities can happen that may cause helpers to question their personal safety, self-efficacy, and worldview based on experiences with 
the clients they serve (Pearlman \& Saakvitne, 1995).

Symptoms of vicarious trauma are synonymous with those manifested by STS. VT encompasses one's own personal experience with trauma as a catalyst for experiencing secondary trauma (Yassan, 1995). Those who have firsthand accounts of similar experiences of their clients may not possess the emotional capacity to provide support for others (Pearlman \& Mac Ian, 1995). Helpers with first-hand experiences of trauma are more likely to become susceptible to vicarious trauma because of the relatability to the experience.

With a myriad of terms for these types of conditions, it is easy to be overwhelmed with identifying specific indicators. In Table 2, Best Start Resource Centre (2012) identifies the various classifications and illustrates the signs of someone suffering from the condition.

\section{Table 2}

Comparison of Burnout, Vicarious Trauma, and Secondary Traumatic Stress

\begin{tabular}{lll}
\hline Burnout & $\begin{array}{l}\text { Vicarious Trauma/ } \\
\text { Compassion Fatigue }\end{array}$ & $\begin{array}{l}\text { Secondary Traumatic Stress/ } \\
\text { Secondary Trauma }\end{array}$ \\
\hline $\begin{array}{l}\text { Cumulative, usually over } \\
\text { long period of time }\end{array}$ & $\begin{array}{l}\text { Cumulative with symptoms } \\
\text { that are unique to each service } \\
\text { provider }\end{array}$ & $\begin{array}{l}\text { Immediate and mirrors client/patient } \\
\text { trauma }\end{array}$ \\
\hline Predictable & Less predictable & Less predictable \\
\hline No evidence of triggers & $\begin{array}{l}\text { May have triggers that are } \\
\text { unique }\end{array}$ & $\begin{array}{l}\text { Often have triggers that are similar } \\
\text { to the client's/patient's triggers }\end{array}$ \\
\hline
\end{tabular}

Table 1 illustrates that there is an intersection of the various concepts, and because of this, victims may experience disturbances from multiple indicators (Figley, 1995; Pearlman \& MacIan, 1995). For purpose and clarity, I will be using the STS 
construct as the word choice to describe the phenomena in this study.

\section{Trauma}

The APA (2013) defines trauma as:

...direct personal experience of an event that involves actual or threatened death or serious injury; threat to one's physical integrity, witnessing an event that involves the above experience, learning about unexpected or violent death, serious harm, or threat of death, or injury experienced by a family member or close associate (p. 271).

Profound events such as accident and illness, loss and grief, physical and emotional abuse, neglect and sexual abuse, and community violence are all examples of traumatic experiences. While trauma is a natural reaction to a devastating event, the effects can be so severe that they interfere with a person's ability to live a normal life.

Carlson (1997) further develops the definition of trauma with three characteristics of traumatic events: the suddenness of the experience, lack of control over the event, and perception that the event is a negative experience. Carlson and Dalenberg (2000) illustrate this delineation with the example of a person who loses their home in a flood. They may not have sustained an injury but might still be so overwhelmed with a sense of fear, helplessness, or horror due to the loss that they are indeed traumatized by the experience. For children, this same feeling of hopelessness and fear can come in response to a divorce, loss of a parent through incarceration, or even homelessness.

The human body's response to trauma can be both physical and psychological (van der Kolk, 2003). Regions of the brain, along with the endocrine system, react to stressors by responding with a fight, flight, or freeze nature that signals systems in the body and releases stress hormones as a way to provide protection and acts in a survival mode (van der Kolk, 2003). An increase in the heart rate intensity, dilated pupils, flushed 
skin, and trembling are all physical responses to traumatic stress. Endocrinological changes become imminent in the body's desperate mission to defend against the negative experience (Sherrin \& Nemeroff, 2011).

The reaction to trauma can lead to unpleasant disruptions with symptoms of traumatic stress that include reminders of the experience (e.g., flashbacks, intrusive thoughts, and nightmares), stimulation (e.g., hyperarousal, agitation, and impulsivity), and avoidance (e.g., numbing, withdrawal, and dissociation) (Sherrin \& Nemeroff, 2011; American Psychiatric Association, 2013). For the majority of persons, these experiences are transient and have a minimal functional impact on an individual (Sherrin \& Nemeroff, 2011). However, for others, traumatic stress has been linked to the development of posttraumatic stress disorder (PTSD) (Margolin \& Gordis, 2000; McCloskey \& Walker, 2000), lower academic achievement (DePrince, Weinzierl, \& Combs, 2009), and behavioral and health challenges (Buka et al., 2001).

The inclusion of PTSD in the DSM-5 promotes recognition of the psychological impact of a single traumatic event. Furthermore, it gives credence to how an individual can have life-altering trauma as a result of one experience. PTSD has been widely recognized as a debilitating, long-term mental health condition suffered by war veterans (Ringel \& Brandell, 2011). Advocates for the mental health of women and children supported adopting this terminology to define disorders experienced by this subgroup as well (Ringel \& Brandell, 2011; Herman, 1992).

\section{Trauma and Children}

While trauma is a natural reaction to a distressing event, the reaction can be varying and significant for children. Researchers have uncovered the devastating impact 
of exposure to trauma on the brains of children who experience childhood trauma (Cloitre et al., 2009; van der Kolk, 2003; Weber \& Reynolds, 2004). Areas of the brain responsible for learning and memory have rapid growth in early childhood, and traumatic experiences can change the structure and way a child's brain functions through the deployment of stress response systems (Bellis \& Zisk, 2014).

Repeated traumatic experiences force children to live in a constant state of emergency. This has significant implications on both brain development and social functioning (Cloitre et al., 2009). Early trauma can cause disruptions to the development of significant functions of learning and adaptation, such as attention, perception, memory, self-regulation, and interpersonal relationships (van der Kolk, 2003). These impairments, in turn, may lead to deficits over time in the areas of attachment, physical health, emotional regulation, dissociation, cognitive ability, self-concept, and behavioral control (Cook et al., 2005).

Trauma can be experienced through direct exposure or indirectly as secondary trauma. Children who witness violence directed at someone they love or care about can experience physiological and emotional stress (Holt et al., 2008). The instability of the home environment can influence a child's self-esteem and lead to self-blame and hopelessness as well as a preoccupation with danger (Briere \& Jordan, 2009).

Child victimization is a significant public health crisis in the United States (Anda et al., 2006). Annually, 1 million children in the United States experience substantiated abuse (U.S. Department of Health and Human Services, 2007). The Federal Child Abuse Prevention and Treatment Act defines child abuse and neglect as:

Any act or failure to act on the part of a parent or caretaker which results in death, 
serious physical or emotional harm, sexual abuse or exploitation; or An act or failure to act which presents an imminent risk of serious harm (U.S. Department of Health and Human Services, 2018, para. 2).

Children who have been exposed to one or more traumas throughout their lives may suffer from child traumatic stress. As a result, they are more likely to develop reactions that persist and affect their daily lives long after the traumatic events have ended. Initial responses to trauma can include confusion, depression, anxiety, dissociation, difficulty eating, sleeping, and acting out (van der Kolk, 2003). Indicators of more severe reactions include persistent fatigue, sleep disorders, fear, and reoccurring flashbacks and violent outbursts (van der Kolk, 2003). The response to a potentially traumatizing event will vary depending on the stage of development, personality, intelligence, and prior history of trauma of the child (Cole et al., 2005).

According to data from the National Center for Mental Health Promotion, $60 \%$ of adults experienced abuse or another mistreatment during childhood. The Adverse Childhood Experience (ACE) study surveyed over 17,000 adult participants in a seminal research study that focused specifically on the impact of childhood exposure to traumatic events. Kaiser Permanente and the Centers for Disease Control (CDC) assessed the prevalence and long-term impact of childhood trauma (Felitti et al., 1998). The study found that $63 \%$ percent of the participants reported experiencing at least one $\mathrm{ACE}$ before the age of 18 years; almost $40 \%$ reported two or more adverse childhood events (Felitti et al., 1998). The results of the ACE study offer insight into the long-term effects of childhood exposure to trauma. Children who have suffered from five or more adverse experiences before the age of 3 have a significant increase in the likelihood of having one 
or more delays in their language, emotional, or brain development. The researchers note that primary, secondary, and tertiary prevention strategies are needed to prevent the occurrence of adverse childhood experiences and mitigate the long-term effects of ACES.

For children who suffer at the hands of a caregiver, the impact can be multifaceted (Cole et al., 2005). Complex trauma refers to a type of trauma that repeatedly occurs over a period of time and within specific relationships and contexts (Courtois, 2004). In most cases, complex trauma exposure is correlated to occurrences of child maltreatment at the hands of a caregiver (Cook et al., 2005; Streek-Fischer et al., 2000). Children rely on their caregivers' attachment for identity development and selfregulation in relation to others (Cook et al., 2005). When the child-caregiver relationship includes neglect or abuse, the attachment relationship is damaged. Attachments that are dysfunctional force the child to rely on inadequate coping skills such as aggression, dissociation, and avoidance (Kinniburgh et al,, 2005). Children whose attachment patterns have been disrupted are more likely to isolate themselves and have trouble with attachment in relationships (Cook et al., 2005).

\section{Poverty and Trauma}

In 2014, approximately 15.3 million, or $21 \%$, of all children under the age of 18 in the United States were in families living in poverty; this population includes 10.7 million school-age 5- to 17-year-olds (Kena et al., 2016). The correlation between poverty and trauma is well-documented (Jensen, 2009; Kiser, 2007; Buka et al., 2001). The challenges students from low-income families face in their homes and communities may accumulate over time, compounding the likelihood of negative effects (Hopson \& Lee, 2011). 
Children living in poor urban neighborhoods inherit a significant risk of exposure to incidents that might lead to traumatic stress disorders due to the social ecology of the environment in which they live (Buka et al., 2001; Kiser, 2007). Jensen (2009) defines poverty as "a chronic and debilitating condition that results from multiple adverse synergistic risk factors and affects the mind, body, and soul" (p. 2).

African American and Latino populations living in urban areas are likely to be exposed to extreme occurrences of trauma. Black/African Americans of all ages are more likely to suffer from (PTSD) (Alim et al., 2006). In a 2001 longitude study by Hurt, Malmud, Brodsky, and Giannetta (2001), approximately 100 7-year-old children were surveyed over three years to assess exposure to violence. Of that number, $75 \%$ had heard gunshots, $60 \%$ had seen drug deals, $18 \%$ had seen a dead body outside, and $10 \%$ had seen a shooting or stabbing in the home. When interviewed, many showed signs of depression and anxiety, with $61 \%$ indicating that they worried some or a lot of the time that they might be killed or die, and 19\% sometimes wished they were dead. The number of children in urban schools who have been exposed to violence increases the likelihood of students impacted by trauma significantly more than schools in suburban settings.

Features of the urban environment increase the risk of trauma exposure and childhood mental health needs (McKay et al., 2005). Anakwenze and Zuberi (2013) write that a bidirectional, cyclic, and reinforcing relationship exists between poverty and mental illness in the inner city as a result of the complex forces that come together amid concentrated urban poverty. Social disorganization and community violence contribute to mental health deficiencies in individuals (Anakwenze \& Zuberi, 2013; Kiser, 2007). 


\section{Trauma and Schools}

In 2013-14, approximately $65 \%$ of public schools logged one or more incidents of violence on the school campus (McFarland et al., 2017). Schools are not immune to the conditions of the neighborhood surrounding them (Kiser, 2007). Many urban schools are embedded in communities with high rates of poverty and crime. The schools inherit the challenges of the communities, including students suffering from trauma.

Poverty has adverse implications on both academic and behavioral challenges in schools. This is significantly due to the stressors of poverty resulting from a lack of resources (Bronwyn \& Suniya, 2002; Raver et al., 2007). Schools with higher concentrations of low socioeconomic status students are correlated with low performance (Orfield et al., 2004). Several studies have found a correlation of less experienced teachers assigned to schools with lower-achieving students (Darling-Hammond, 2000; Lankford et al., 2002; Rivkin et al., 2005). In addition, students from marginalized backgrounds are less likely to be exposed to experienced and highly qualified teachers. According to Borg, Borg, and Stranahan (2009), in high-poverty schools, there is a lower proportion of teachers who hold advanced degrees, and these teachers have fewer years of experience. The researchers found that teacher turnover is much higher in high-poverty schools, which leads to teachers with fewer years of experience. Teachers are more likely to leave the profession in their first year in schools with a high-poverty student population (Gray \& Taie, 2015; Johnson et al., 2004). As a result, teachers in urban schools are less likely to meet at-risk populations' needs due to experience and lack of training.

Studies have revealed that early trauma can affect a child's healthy growth and 
development (Cloitre et al., 2009; Lansford et al., 2002), making it challenging for the child to establish and keep satisfying relationships with peers and adults, achieve selfregulation, and access cognitive skills and processes that facilitate learning. Many educators have experienced students in their classrooms with a history of trauma who display intense reactions when an authority figure redirects behavior. The traumatized child may fear that they will be harmed and, in turn, react with violent, emotional outbursts that may include striking staff or other students (National Child Traumatic Stress Network Schools Committee, 2009). This reaction is partly because children who have experienced rejection, abuse, or neglect from their caregivers are likely to respond with avoidance or aggression when faced with overwhelming experiences. This display of aggression can be traumatizing to educators. Several studies have shown that a key factor for leaving the teaching field is the challenging behavior of students (Ingersoll \& Smith, 2003; Kelly, 2004).

Children who have experienced trauma are more likely to act out in unfamiliar situations or structured environments such as a classroom. These students may be unable to focus on class activities and appear to be inattentive and uncooperative due to their constant fear. This can cause lasting emotional harm to the child's ability to establish relationships with teachers and peers.

Traumatized children often have an inability to bounce back from hurt and anger. These children also may behave in negative ways that are subject to correction by their teachers which further exacerbates their ability to trust and build attachment relationships (Davies, 2004). Often, the children lack the ability to elicit comfort when faced with stress (Lyons-Ruth et al., 1993). Many times, this is a result of inconsistent, unstable, and 
unsafe relationships with caregivers. These students view themselves as bad and incapable of expecting others to view them as anything less than negative. The cycle often continues to work against them, as their aggressive behavior is likely to be rejected by peers and identified by teachers as a behavior problem (Davies, 2004).

\section{Schools as Mental Health Facilitators}

Schools have long been considered the gateway for assessment and facilitators of mental health services for the students they serve. It is estimated that approximately one in five children have mental health service needs (National Research Council and Institute of Medicine, 2009). Often schools are the initial setting where behaviors manifest, signaling that something is awry. Aggression and disruptive behavior and behavioral problems associated with neurological disorders are cited as significant factors for referrals to school-based mental health services in elementary schools (Foster et al., 2005).

The school provides the ideal venue for the delivery of mental health services. Student attendance is compulsory, and for many families, the school may be less stigmatizing than hospitals or clinics. Nearly $70 \%$ of the children who receive mental health services receive their care through the education sector (Farmer et al., 2003; Hoagwood et al., 2007). However, the proportion of students in need of mental services continues to outpace available resources, even when the services are available in schools (Hoagwood et al., 2007).

The "School Mental Health Services in the United States, 2002-2003" (Foster et al., 2005) was the first national study to provide information about schools' role in providing mental health services. The study examined how these services are organized, 
staffed, funded, and coordinated. Findings from the study showed schools typically provide socio-emotional support, with an estimated majority (63\%) providing universal supports as a preventive intervention to take a proactive approach in addressing student needs. The research also found that $59 \%$ of the schools surveyed offer services for children demonstrating behavior problems. The study cited a diverse assortment of service delivery models that range from the exclusive use of school staff that provides services to students, to schools that contracted services with outside providers, to a combination of both. Over half of the schools reported having formal arrangements with one or more community-based organizations or individual providers for student mental health services.

The research on the positive impact of mental health services in schools is as diverse as the implementation models. Program type and quality were based on the available funding for resources. Foster et al. (2005) proposed that further research is needed to identify the causes and effects of varying fund distribution that dictate the service's type and quality. The study also encouraged further exploration into the effectiveness of individual mental health services and school-wide prevention and intervention services.

\section{Secondary Traumatic Stress Among Urban School Educators}

Teachers in urban schools are often unprepared for the stressors that stem from working with traumatized students. High-poverty schools serve as the setting for elevated populations of students who have experienced trauma (Wadsworth et al., 2008). Many students who have experienced trauma have developed a sense of hopelessness and complacency that manifests in aggression, impulsiveness, and opposition toward fellow 
students and staff (Zyromski, 2007).

Interestingly, the urban school setting's correlation breeds the conditions that make some teachers more susceptible to STS. New teachers and teachers with high exposure to traumatized students are more likely to be emotionally impacted when encountering recollections of their students' circumstances. Figley (1995) established that empathy is a mediating factor for experiencing secondary traumatic stress among individuals who are working with the traumatized. Teachers who exhibit concern and empathy for the conditions of their students' home environments are vulnerable to STS (Hill, 2011).

Like the students they serve, STS has unique characteristics that signal an educator to develop it. The educator may display a sense of helplessness for professional duties, irrational fear associated with a student's traumatic experience, or obsession with a student's situation. Teachers often feel compelled to reach out to help students with a heightened sense of empathic awareness, making them vulnerable to STS (U.S. Department of Education, 2012). This intense desire to help others may cause them to neglect their own needs and emotions. Another signal of STS in educators can be when school personnel push themselves too hard to get things done and try to do it all on their own. Many of these indicators can be more apparent to others than the individual exposed to STS. Colleagues may become aware of symptoms such as increased irritability, isolating oneself from others, or becoming easily agitated or annoyed (Hydon et al., 2015).

In a study by Abel and Sewell (1999), 51 rural and 46 urban schoolteachers from 11 school systems in Georgia and North Carolina were asked to complete a 
questionnaire to identify sources of stress and a survey to measure teacher burnout. The results revealed significantly higher self-reported stress for urban schoolteachers. Interestingly, the urban school setting breeds the conditions that make some teachers more susceptible to secondary trauma.

\section{Self-Care}

Secondary traumatic stress influences the individual both personally and professionally. It is a natural byproduct of working with individuals who have experienced trauma. The employees' symptoms can lead to a diminishing ability to work with the clients they serve. Researchers of STS suggest a variety of strategies to reduce the symptoms of the phenomenon (Bober \& Regehr, 2006; Middleton, 2015). The teacher who cannot respond effectively to a child with emotional outbursts as a result of trauma jeopardizes the child's well-being and may cause additional harm.

Self-care refers to activities initiated and performed by an individual with the intention of improving health, preventing disease, or maintaining their well-being (Orem, Taylor \& Renpenning, 2001). Few studies have explored the impact of coping strategies to provide self-care to those who work with people who have experienced trauma. One multimethod study examined the effectiveness of eight weeks of training in increasing self-care, awareness, and coping strategies for 12 human service workers (McGarrigle \& Walsh, 2011). Paired t-tests conducted on pre- and post-training scores on the Perceived Stress Scale and the Mindfulness Attention and Awareness Scale showed that mindfulness significantly increased and that stress significantly decreased over the intervention period.

In another study conducted by Salloum et al. (2015), 104 child welfare case 
managers and supervisors from a large private child welfare organization in South Florida were surveyed on self-care management's effectiveness. The researchers used several data instrument surveys to measure burnout, compassion fatigue, and compassion satisfaction. In addition, a trauma-informed self-care (TISC) tool was used to determine the role of self-care strategies to determine worker retention and engagement.

The findings from this study identify symptoms of secondary trauma require intensive treatment interventions to assist with recovery. Findings from this study are similar to outcomes of other studies (Bober \& Regehr, 2006; Hoffman et al. , 2007; Killian, 2008) that implied a systematic transformation of workplace environments should be explored when pairing TISC to ensure employees have the supports necessary to employ the self-care management strategies. The studies suggest providing training to promote wellness plans.

One particular study looked at a toolkit put together by two researchers in partnership with the United States Department of Education, working alongside district administrators, following Hurricane Katrina in New Orleans (Hydon et al., 2015). Five years following the destruction caused by the hurricane, the city was once again hit with an event that created uncertainty and economically impacted many of the families and staff. Educators who were already showing signs of exhaustion from supporting students during the initial devastation were approaching energy depletion and were showing signs of trauma themselves.

Using a multilevel approach, the district provided training that included a selfcare component, utilizing a holistic approach. The facilitators provided meaningful definitions of compassion fatigue, STS, VT, and psychological burnout to diminish any 
stigma or clarify any ambiguity in the terminology. They allowed the educators to recognize

STS signs and the salient conditions that may make them vulnerable to the condition. Participants

were given the option to share how they were feeling in the group sessions or individual

counseling opportunities. The goal for the training was to convey to the educators that

they should acknowledge the feelings they were having. Worksheets were provided,

allowing participants to reflect on six areas for improving health and well-being. They

included social, physical, intellectual, financial, spiritual, and financial well-being. In

Table 3, Hydon et al. (2015) identify the areas and types of activities educators can

engage in to promote self-care.

\section{Table 3}

Activities to Promote Self-Care

\begin{tabular}{ll}
\hline Self-Care Focus & Activities to Promote Well-being \\
\hline Social Self-Care & $\begin{array}{l}\text { This type of self-care can take on many forms, such } \\
\text { as belonging to positive social networks; maintain } \\
\text { relationships with friends; attending social } \\
\text { activities or events. }\end{array}$ \\
\hline Physical Self-Care & $\begin{array}{l}\text { Physical self-care encompasses appropriate } \\
\text { exercise; proper eating habits; proper amount of } \\
\text { sleep; joining gyms or exercise clubs }\end{array}$ \\
\hline Intellectual Self-Care & $\begin{array}{l}\text { Intellectually stimulate self-care include reading } \\
\text { books; attending workshops or seminars; } \\
\text { learning a new craft or developing a new hobby. }\end{array}$ \\
\hline Financial Self-Care & $\begin{array}{l}\text { Financial self-care is something that takes a } \\
\text { disciplined commitment and includes such items } \\
\text { as: itemizing bills; monitoring expenses; } \\
\text { incorporating expenses for leisure activities; talk } \\
\text { with a financial consultant. }\end{array}$ \\
\hline Spiritual Self-Care & $\begin{array}{l}\text { Spiritual Self-Care often can resonate with some } \\
\text { spiritual being or a Higher Power. Spiritual self- } \\
\text { care can be very uplifting and may include } \\
\text { taking steps to reconnect with your Higher } \\
\text { Power; attending religious services; participating } \\
\text { in study groups; daily reflection on life purpose. }\end{array}$ \\
\hline $\begin{array}{l}\text { Commitment to surrounding self with healthy } \\
\text { environments such as taking a walk outdoors; } \\
\text { creating a specific space in the home that is }\end{array}$ \\
reserved only for healthy activities or rest; \\
camping or contributing to an environmentally \\
sound cause.
\end{tabular}


Hydon et al. (2015) suggest that more opportunities exist to expand this project nationwide. Teacher preparatory programs and schools should prepare educators to know the signs of STS.

One should not assume that the prevention of STS is solely the role of the individual (Yassen, 2009). Yassen (1995) provides an ecological model that highlights the interaction of the individual and environmental influences of STS prevention. Using an ecological approach draws on the science concerning the interrelationship of organisms and the environment around them. Primary prevention efforts are joint responsibilities of policymakers, district administrators, and principals, as well as the individual. Figure I illustrates how educators can make personal commitments as protective factors while also providing considerations for the larger environmental implications. 


\section{Figure 1}

Ecological Model for the Prevention of STS

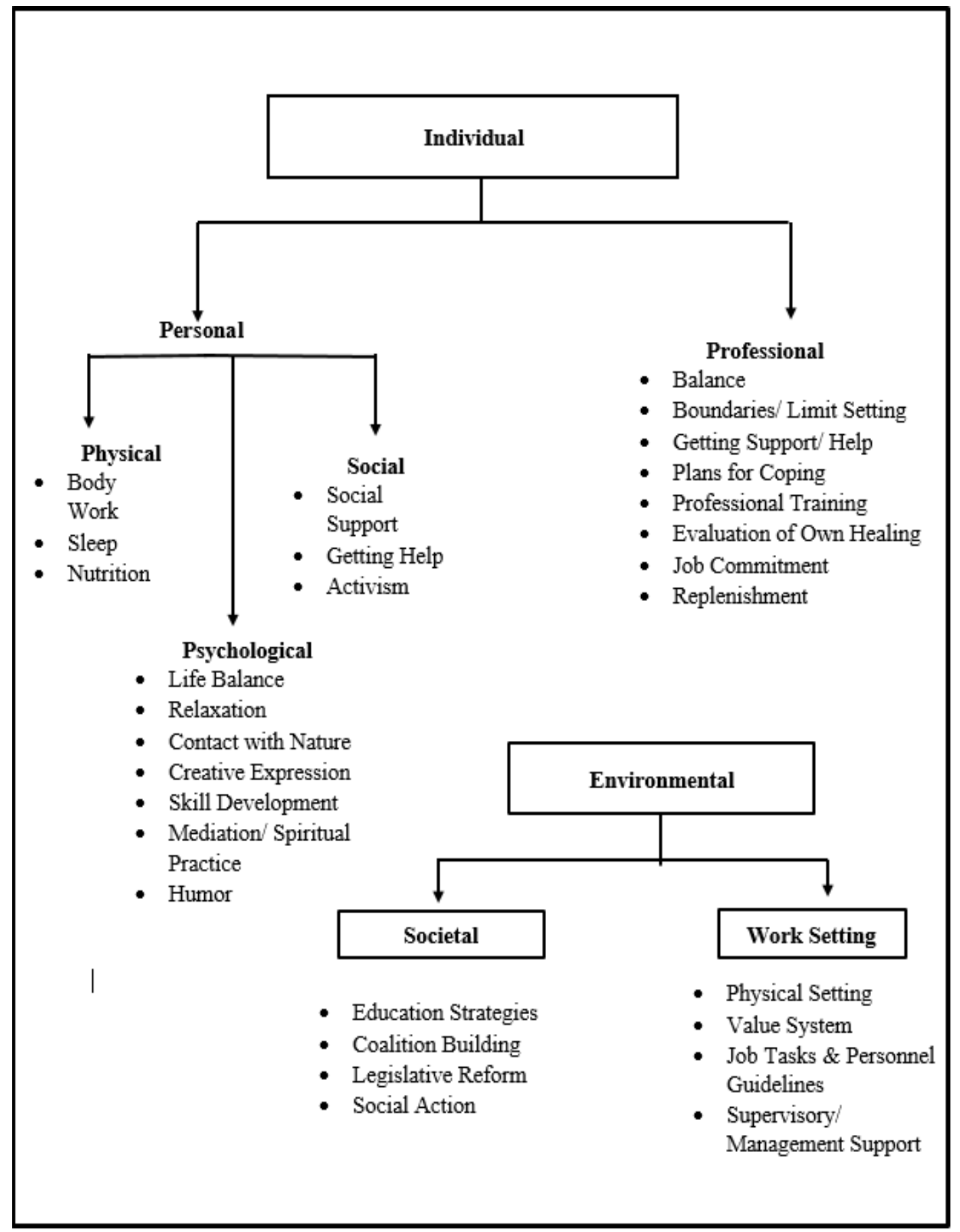

Note. From Ecological model for the prevention of STS Yassen, J. (1995). Preventing 
Secondary Traumatic Stress Disorder. Compassion fatigue: Coping with secondary traumatic stress disorder in those who treat the traumatized

\section{Summary of the Literature Findings}

Although researchers have assigned different labels (e.g., STS and VT) to identify varying aspects of the occurrences, the labels all seem to represent the same phenomenon (Bride, 2007). This phenomenon has been examined through numerous studies for first responders, such as law enforcement officers, emergency medical personnel, firefighters, and counselors and therapists (Bride, 2007; Figley, 1995; Pearlman \& Mac Ian, 1995). Very little research examines the impact of secondary trauma on educators specifically.

Much of the research methodology for the studies used a qualitative approach. The researchers predominantly interviewed participants. Because the way a person responds to trauma can vary, the qualitative method allows the participant to have the flexibility to expand on the responses in the context and manner they choose.

Hill (2011) noted in a recent study that teachers felt unprepared for their work and advocated that school staff members receive additional training in working with traumatized students. The author went on to write that more research should be replicated to see if the findings are consistent with the study. The implications may provide a better understanding of the phenomena and opportunities to support educators.

Educators who begin to have altered views of the world around them due to the experiences with traumatized children can have temporary or long-lasting changes occur. This manifestation signifies the magnitude of how secondary traumatic stress can affect educators. It is essential to bring awareness to the education community. Before appropriate policies and practices can be developed to address educators' needs, a comprehensive awareness of the influence of secondary trauma on educators should be 
established.

This study will explore the lived experiences of elementary teachers working with students who have been exposed to trauma - how the exposure influences the educators, and in what ways they cope and process the knowledge of students' experiences. 


\section{CHAPTER III}

\section{METHODOLOGY}

\section{Introduction}

The purpose of this qualitative study was to explore the lived experiences of elementary teachers working with students who have experienced traumatic events. Educators who teach in schools with a high population of at-risk students have a greater likelihood of STS (VanBergeijk \& Sarmiento, 2006). This study sought to discover how urban elementary teachers cope with and manage these lived experiences. I hope that this study will encourage school districts to bring awareness of secondary traumatic stress to educators and support teachers in managing this phenomenon. Creswell (2014) identifies qualitative research as:

... an approach for exploring and understanding the meaning individuals or groups ascribe to a social or human problem. The research process involves emerging questions and procedures, data typically collected in the participant's setting, data analysis inductively building from particulars to general themes and the researcher making interpretations of the meaning of the data (p. 4).

In an effort to best understand how educators process knowledge of their students' traumatic experiences and cope with the emotional toll of learning of their student's experiences, I posed the following research questions: 
1) How do educators acquire information about their students' traumatic experiences?

2) How do the lived experiences of elementary teachers working with students who have been exposed to trauma influence the educators?

3) How do teachers cope with and process their experiences of working with traumatized students?

In this chapter, phenomenological research will be explained, along with my rationale for establishing a phenomenological approach to this study. I will describe how participants were recruited and discuss my interview protocol, ethical considerations, limitations, and delimitations. Lastly, I will conclude with my process of collecting and analyzing the data from the interviews with my study participants.

\section{Research Approach}

I used a phenomenological research approach for this study. The aim of this type of approach is to get the "essence of each participant's experiences and perceptions of a phenomenon and make meaning by discovering similarities and differences among the cases" (Glesne, 2016, p. 290). Phenomenological research relies on first-person accounts in informal and formal conversations and interviews as the data for scientific investigations (Moustakas, 1994).

Phenomenology is based on German mathematician Edmund Husserl's philosophical fundamentals and expanded on by philosophers Heidegger, Gadamer, Merleau-Ponty, and Sartre. Creswell (2013) explains, "A phenomenological study describes the common meaning for several individuals of their lived experiences of a 
concept or phenomenon" (p. 76). Utilizing phenomenological methods with educators on this phenomenon where little research currently exists will allow the voices of those experiencing secondary trauma to be revealed.

Van Manen (2007) uses this eloquent description to illustrate phenomenological research:

Phenomenology is a project of sober reflection on the lived experience of human existence - sober, in the sense that reflecting on experience must be thoughtful, and as much as possible, free from theoretical, prejudicial and suppositional intoxications. But, phenomenology is also a project that is driven by fascination: being swept up in a spell of wonder, a fascination with meaning" (p. 12).

Porter and Cohen (2013) identify three approaches to conducting phenomenological studies - descriptive phenomenology, interpretive phenomenology, and hermeneutic phenomenology. The aim of the researcher utilizing descriptive phenomenology is to "explore and describe the essential structure of an experience in terms of the phenomena" (Porter and Cohen 2013, p. 182). This method is common among researchers across various disciplines and is commonly associated with Colaizzi and Giorgi's works (Porter $\&$ Cohen, 2013). Interpretive phenomenological researchers seek to understand and interpret the experiences of the participants (Tuohy et al., 2013). Using this method, "frequently taken-for-granted shared practices and common meanings" are extracted during data analysis (Porter \& Cohen, 2013). Hermeneutic phenomenological researchers go a step further and combine features of both descriptive and hermeneutic methods by incorporating how participants interpret their lives and come to understand the experiences of the phenomena (Porter \& Cohen, 2013). 
In this study, I explored teachers' lived experiences working with students who have experienced trauma using a hermeneutic phenomenology method: How does this work influence the educator, and how do they manage or cope with the knowledge of their students' experiences? The phenomenological design allowed for a detailed description of the participants' themes and patterns through their own voices.

Hermeneutic phenomenological research begins with "turning to a phenomenon, which seriously interests us and commits us to the world" (van Manen, 1990, p. 30). My personal experiences pique my interest in exploring secondary trauma with educators.

An extensive review of research studies yields overwhelming evidence that interviews are a commonly used method in phenomenological research (Edwards \& Holland, 2013; Bevan, 2014). I engaged with the participants through direct face-to-face interviews as they shared their stories. I asked follow-up, probing questions based on the unique experiences of each person. One-to-one interviews allow for privacy and confidentiality assurance (Wellings et al., 2010).

\section{Theoretical Framework}

Ultimately, this study uses the STS framework to investigate the experiences of educators working with traumatized students. It is important to bring meaning to those experiences. Social constructivists believe that knowledge is acquired by interactions with other people and their environment (Schunk, 2012; Vygotsky, 1998). I used social constructivism as an additional theoretical framework for this study. Social constructivism is a common worldview in qualitative studies (Creswell, 2014). Researchers emphasize the participant's views and interpretations of the situation or phenomenon being studied. Crotty (1998) identifies social constructivism as focusing 
primarily on the individual's ability to make meaning of a concept. With semi-structured interviews, I looked for themes among the participants' reflections of what educators might experience to illuminate secondary trauma's influence among educators.

Ultimately, I wanted to provide research that leads to effective practices that improve the lives of educators who work with students who have experienced trauma.

\section{Research Context and Positionality}

Several factors influenced my interest in conducting this study. I have served as an educator for over 20 years. My experience has been without exception in schools that have a high concentration of Title I students. Over the years, I have worked with a number of students who have experienced trauma. I have personally felt the weight of supporting students who have trouble coping with their exposure to trauma. The experiences with my students have influenced me, both emotionally and physically. During my tenure as an elementary school principal, I slowly watched as teacher after teacher cracked under the pressure of the challenges of working with our students and their families. Despite the support and training provided to my staff around instructional practices, I could not keep staff from transferring at the end of each year.

This connection is essential to identify as a phenomenologist researcher. I set aside my experiences, biases, and assumptions. This method is known as epoche or bracketing reduction. Epoche provides the researcher with a "vantage point, a clearing of mind, space and time" (Moustakas, 1994, p. 86). This research practice is essential so that my own experience with the phenomena does not influence me. This allows me to gain insight from a fresh perspective. 


\section{District Context Setting}

This research took place in Central City Public Schools (CCPS), a large urban school district. According to established data provided by the district, $64 \%$ of the schools qualify for Title I funding. Six of the elementary schools in CCPS have a student enrollment in which $90 \%$ or more of the students are eligible for free and reduced meals. The enrollment for these schools ranges from 195 to 370 students.

\section{Sample Design and Size}

The study focused exclusively on elementary teachers because of the length of time they have with their students each day. Often, students arrive in their classrooms early in the morning and continue most, if not all, of their days with the same teacher. As a result, the elementary teacher plays a significant role in the child's emotional and social well-being, including managing the emotional burden of dealing with childhood trauma manifestations.

I recruited teachers from the seven schools identified in the district research data, with $90 \%$ or more students who qualify for free and reduced meals. Phenomenological studies do not have a prescribed number of participants; however, Creswell (2013) suggests up to 10 participants for studies that include lengthy interviews. I selected a sample size of 10 subjects for my study.

Following university Institutional Review Board (IRB) approval, I submitted a research request to the district's data management system to obtain access to perform research within the school district. This department serves as the gatekeeper for formal requests to complete research in the school district. I then emailed a recruitment letter (Appendix A) to all elementary teachers of selected schools who have served three years 
or more in the current school. According to the recruitment letter's questionnaire, recruits had to self-identify that they may have experienced secondary traumatic stress. The letter briefly described the scope of the study and a request for their participation. It also contained the criteria for participation and an opportunity to allow the participant to selfreflect to determine if they believe they have experienced secondary trauma. The Informed Consent form (Appendix B) was presented to participants who agreed to participate in the study. Included in the consent was full disclosure of the study's purpose, the methods that would be used for data collection, and the participant's rights to discontinue the study at any time. Participants were asked to sign the document as confirmation of receipt of this information.

\section{Ethical Considerations}

Kaiser (2009) illustrates the challenge qualitative researchers face in their desire to convey detailed, accurate accounts of the social world while ensuring the protection of participants' identity in a given study. To maintain the confidentiality of the participant, pseudonyms were used throughout the study. As the researcher, I have sole ownership of each participant's assigned pseudonym that links to each participant's name. Information that links the participants to their assigned pseudonym is kept in an encrypted document on a password-protected computer.

During the study, sensitive information about students and the participants themselves was revealed. To ensure confidentiality of all parties, the transcripts from interviews were destroyed following the completion of the study. As an added layer of protection, all transcriptions were captured and secured on a password-protected computer. 
Due to the subject matter's reflective nature, I paid great attention to looking for the participant's potential emotional distress. If a respondent showed signs of emotional distress during the study, I was prepared to suspend the interview and offer them a list of behavioral health specialists for consultation (Appendix D). These agencies are well recognized in the local community.

\section{Data Collection}

Data for this study was collected by conducting face-to-face interviews with 10 elementary teachers in high-poverty schools. In an effort to respect the candidates and be actively attentive to the responses, all interviews were audio-visually recorded. Recording the session was also essential for later transcribing for data analysis. A professional online transcription service transcribed the audio files of the participant interviews.

The interviews were semi-structured by design utilizing a set of questions adapted from a study by Hill (2011) (see Appendix C). Glesne (2016) suggests that in semistructured questioning, the interviewer should establish a set of questions, be open to restructuring, add to the questions, and incorporate in-depth probes in response to the participant during the interview sessions based on the unique experiences of the individuals. Although the interviews vary in length, they were capped to 90 minutes to respect the participants' time.

\section{Data Analysis}

Creswell (2014) describes a systematic process for coding data from a phenomenological inquiry in which specific statements are analyzed and categorized into clusters of meanings that represent the phenomenon of interest. Data analysis is an interpretive process (Glesne, 2016). Moustakas (1994) suggests making meaning of the 
lived experiences by extracting themes from the narratives. The analysis was conducted using the data collected from interviews with elementary teachers to identify themes of how working with traumatized students influences the educator.

As part of the data analysis process, I took a small chunk of the text and conducted line-by-line coding. Significant statements that identify the participant's response to the experiences of working with students exposed to trauma were identified, and key phrases were noted. The concepts are named, another chunk of text was then taken, and the steps mentioned above were repeated. Over time, this process broke the data into conceptual components.

\section{Trustworthiness}

Many researchers argue the appropriateness of the term validity in qualitative research (Golafshani, 2003). Terms such as trustworthiness and quality have manifested as suitable measures of validity in qualitative studies. Qualitative research requires researchers to be explicit regarding the methods used to establish the credibility of the interpretations of the data for the study (Cutliffe \& McKenna, 1999).

To ensure credibility in my research, I used member checking to verify the accuracy of what was captured during the interviews. Once the recorded interviews were transcribed, the teachers interviewed were given an opportunity to review them for accuracy. Glesne (2016) states that the words, descriptions, and thoughts acquired through research are not meaningful in themselves, but rather the interpretation and data analysis gives meaning to the study. Member checking was also used to examine the validity of my interpretation of their statements and feelings. I provided a summary of the findings for review by the participants before completing the study to confirm I 
captured what the participants wanted to say. Member checking after transcribing and after the analysis ensured that the study is credible as certified by the subjects who participated in the study. Bracketing of my own assumptions and biases of the phenomena also kept the data trustworthy and authentic to the evidence collected in this study.

\section{Summary}

The intent of my study is to illuminate the influence of secondary trauma among urban elementary educators. Educators currently receive very little preservice training in working with children exposed to trauma. Future implications of this study include increasing awareness of secondary trauma among the education community. Preservice coursework should include discussions of warning signs and coping skills for managing secondary traumatic stress. 


\section{CHAPTER IV}

\section{FINDINGS}

The purpose of this phenomenological study was to explore the lived experiences of elementary teachers who work with students who have been exposed to trauma. I wanted to hear the voices of the educators who serve on the "frontline" in their classrooms, where the emotional toll of responding to students can be overwhelming. There is significant research to support the argument that first responders, CPS workers, and others in similar professions are susceptible to STS (Figley, 1995; Bride, 2007). As a result, protective factors are promoted by these occupations to ensure employees know the warning signs and pathways to seek treatment. Unfortunately, that advisory is not afforded to educators in the same manner. In this study, I hope to provide findings to illustrate the importance of bringing an awareness of secondary trauma among educators and providing tools to assist them in self-care. I pose the following research questions:

1) How do educators acquire information about their students' traumatic experiences?

2) How do the lived experiences of elementary teachers working with students who have been exposed to trauma influence the educators?

3) How do teachers cope with and process their experiences of working with traumatized students?

This chapter summarizes the findings from interviews conducted with 10 elementary teachers from a large urban school district. The beginning of the chapter 
describes the participants. I then present the findings from the data collected from interviews according to the following: 1) the kinds of traumatic events experienced by students; 2) how teachers acquire information about student's experience with trauma; 3) the personal impact of working with traumatized students; and 4) how educators cope with the experiences.

\section{The Participants}

Ten elementary educators participated in this research study. All participants had a minimum of three years of teaching experience in a school with at least $90 \%$ of the students qualifying for free or reduced meals. I initially considered educators with five years of experience, but due to the high turnover in schools meeting this criterion, I had to change the years of experience to have a satisfactory pool to conduct the study.

An initial phone interview was conducted for participants that responded to the recruitment letter. During the call, participants confirmed that they self-identified with the characteristics of secondary trauma. One commented:

I never connected the things that were happening to me physically as a result of working with my students as a type of trauma. But when I saw the recruitment information and it listed the symptoms, I was like — that's me. I can identify with this.

The demographics of the sample were diverse in gender, years of experience, and backgrounds. Some came to the teaching profession through the traditional route with a four-year degree, while others took other pathways before coming to the classroom. However, it should be noted that the majority of the participants were white female educators. This is in line with the overall workforce of educators in the district and across 
the county. Table 4 outlines the varying contextual settings. To protect the privacy of participants, pseudonyms are used.

\section{Table 4}

Participants

\begin{tabular}{|c|c|c|c|c|c|}
\hline Name & Gender & Ethnicity & $\begin{array}{l}\text { Years of } \\
\text { Experience }\end{array}$ & $\begin{array}{l}\text { Traditional } \\
\text { Pathway }\end{array}$ & $\begin{array}{l}\text { Nontraditional } \\
\text { Pathway }\end{array}$ \\
\hline Jerome & $\mathrm{M}$ & B & $\begin{array}{l}18 \\
3 \text { years at } \\
\text { current school }\end{array}$ & & $\begin{array}{l}\text { X } \\
\text { Paraeducator prior } \\
\text { to pursuing } \\
\text { teaching } \\
\text { certification }\end{array}$ \\
\hline Amy & $\mathrm{F}$ & A & 5 & & $\begin{array}{l}\mathrm{X} \\
\text { Substitute prior to } \\
\text { receiving teaching } \\
\text { certification }\end{array}$ \\
\hline Kayla & $\mathrm{F}$ & W & 4 & $\mathrm{X}$ & \\
\hline Angie & $\mathrm{F}$ & W & 10 & & $\begin{array}{l}X \\
\text { Substitute prior to } \\
\text { receiving teaching } \\
\text { certification }\end{array}$ \\
\hline Tiffany & $\mathrm{F}$ & $\mathrm{W}$ & 6 & $\mathrm{X}$ & \\
\hline Renee & $\mathrm{F}$ & W & 4 & $\mathrm{X}$ & \\
\hline Susan & $\mathrm{F}$ & $\mathrm{W}$ & 15 & & $\begin{array}{l}\mathrm{X} \\
\text { Substitute prior to } \\
\text { receiving teaching } \\
\text { certification }\end{array}$ \\
\hline Chelsea & $\mathrm{F}$ & W & 5 & & Second career \\
\hline Ben & $\mathrm{M}$ & W & $\begin{array}{l}9 \\
6 \text { years at } \\
\text { current school }\end{array}$ & & Second career \\
\hline Melissa & $\mathrm{F}$ & $\mathrm{W}$ & 14 & $\mathrm{X}$ & \\
\hline
\end{tabular}

\section{Traumatic Events Experienced by Students}

Teachers could quickly recall the types of trauma that their students have faced.

Domestic violence, shootings, separation from parents due to abuse or drug use or incarceration, and sexual abuse were common responses among the participants. Susan, 
an early primary teacher, talked about the types of exposure experienced by her students:

[My] students over the years have witnessed violence around them — fights domestic abuse, drug use, and other issues. Some of them have been victims. The kids come in with black eyes or marks around their arms and sexual abuse, homelessness, not enough food or clothing, or resources. Drug use and alcoholism [in the home] — all sorts of trauma.

Melissa, a fourth-grade teacher, shared:

I've had students that have had a mental illness, in and out of [intensive support facilities]. I've had children that have been exposed to abuse in the home with parents with each other, and with parents with significant others. They've been exposed to the drugs [and] the violence of relatives and family members dying [and] sexual abuse. I've had students that have literally been sitting in my room during an active period in their life of sexual abuse, waiting for CPS to figure [it] out. I've had kids that had suicidal [thoughts]. I've had kids that come in with bruises and things that we've had investigated and found to be substantiated. Kids removed from the home. Traumatic kids that have jumped from home to home. This summer I had an incident where a student and his brother were held hostage at gunpoint by the mother's boyfriend. He is about to get out [of jail] and that's very traumatic for [the student].

First-grade teacher Tiffany spoke to the sheer volume of the students she has worked with who have experienced trauma:

[I have had] students with parents who've been incarcerated. A lot of my kids live with an aunt or grandparent. I've had kids who have been abandoned by their 
parents. Now depression has been a thing with some of them and crime and drugs.

It's been a whole lot.

Table 5 identifies the kinds of traumatic experiences educators reported.

\section{Table 5}

Types of Abuse

\begin{tabular}{ll}
\hline Participant & Types of Abuse Reported \\
\hline Jerome & \\
& Loss of a brother to gun violence, death of a caregiver
\end{tabular}

\begin{tabular}{|c|c|}
\hline Amy & $\begin{array}{l}\text { Violent death of a relative (brother shot), abandoned by a parent, witnessed brother } \\
\text { murdered by mom's boyfriend }\end{array}$ \\
\hline Kayla & Witnessed death, abandonment \\
\hline Angie & Death of a parent or significant caregiver, domestic abuse, incarcerated parent \\
\hline Tiffany & Incarcerated parent, abandonment, parent involved in a robbery, homelessness \\
\hline Renee & Incarcerated parent, kidnapped, parent murdered (shot), homelessness \\
\hline Susan & $\begin{array}{l}\text { Caregiver arrested, homelessness, child abuse (black eye, marks), food insecurity, } \\
\text { drug use, sexual abuse }\end{array}$ \\
\hline Chelsea & $\begin{array}{l}\text { Shootings, domestic violence, father killed by police, parent incarcerated, mother } \\
\text { overdosed, parent and grandmother died in the same week }\end{array}$ \\
\hline Ben & $\begin{array}{l}\text { Violent death of a relative (brother shot), abandoned by a parent, domestic abuse, } \\
\text { drug use }\end{array}$ \\
\hline Melissa & $\begin{array}{l}\text { Domestic abuse, exposed to drugs, sexual abuse, removed from parent, held at } \\
\text { gunpoint, foster home }\end{array}$ \\
\hline
\end{tabular}

All reported playing a supportive role in providing interventions, such as contacting child protective services or connecting families with therapeutic agencies. Jerome, an 18-year veteran of the school district serving in several high-poverty schools, recalled how he sought support from the school counselor for a student who was mourning a caregiver's loss. Her grief had manifested into not completing assignments or 
participating in class.

It became very clear that all of the educators have encountered students who have been exposed to trauma. One participant even acknowledged that she had not taken the time to reflect on how many students she had encountered with trauma. The question had forced her to recall, and she was astonished at how many children there were.

\section{How Information Is Acquired}

The educators acquired information about the traumatic experiences of students in a variety of ways. One commonality among all 10 participants was that their students often reveal traumatic events that occur in their lives. All attribute the intentionality of establishing relationships with the children in their classrooms to develop a communication venue. Teachers talked of systems such as greeting students at the door, reflection and sharing time embedded in the delivery of instruction (e.g., morning meeting), and other efforts that encourage students to share personal stories of events occurring in their lives. The intimate details often spill out from students. Susan shared:

I can't tell you how many times we were in morning meetings and kids would relay what happened on the weekend or the night before. It was heavy stuff. Kids would say things like, "The police came to our house and took my mom's boyfriend." It was like a regular conversation.

She went on to share a conversation she had with a student who arrived at school with obvious signs that he had been harmed:

I think my first week was kind of a wake-up call. A little boy came in with a black eye. He came to show me his eye, and I was like, "What happened? Are you okay?" He said, "Yeah. I couldn't find a shoe." And so I say, "You got a black eye 
because you couldn't find your shoes?" And he's like, "Yep." I reported it to the authorities. I think that was my first disappointing experience. Later that week, the kid comes in with a new mark. When I ask him about it, the student responds, "Oh, my dad told me I can't tell you about that anymore."

Tiffany reported:

A lot of times, the kids aren't shy. I have only run into one instance where the sister was kind of trying not to say too much, but the younger ones — they are like open books a lot of times.

When students are hesitant to talk to the teachers, they often confide in their peers. Amy recalled a time when a group of girls in her class brought a student to her who had shared a terrifying incident that occurred over the weekend:

They came running up to me. Keep in mind these are 6 and 7-year-olds. They share that their friend is crying. So I am talking with the student and learn that over the weekend, someone was shot. After getting permission from her, I called home and spoke with a guardian. She confirms that it was so and they indeed had been shot. It was just a lot.

The educators indicated that student behavior often signaled that students were exposed to traumatic events. Jerome shared, "I do a lot of observation and just know my kids. That relationship that you build - you can tell something is wrong with them just by looking at them for that whole vibe: something is wrong."

Melissa talked about observing disruptive behavior from a student that followed a particular pattern:

She would misbehave and all of her behavior issues were always toward the end of 
the day, which is another key thing to me. She's not wanting to go home. A couple of times she was like, "Can you take me home? Can I just live with you?"

Chelsea remembers when one of her students' father was murdered. She recalled watching him slide into peril with erratic behavior that led to outbursts and ended in sobs: "It was obvious he needed help."

Tiffany recalled a year-long challenge supporting a student:

I had a little boy who was really sweet. He would be great and then all of a sudden that switch would flip, say, and [he would] do the weirdest stuff. We learned his mom was involved in a robbery gone wrong, and they ended up murdering the guy that was robbed. So she was incarcerated.

Sometimes the evidence of exposure plays out in a way in which students are being conditioned to play a role in nefarious acts. Ben recalls hearing a conversation among two second-grade girls in his classroom:

"I had to pee in a cup ... last night."

"Oh, your mama is trying to pass a drug test?"

"No, my aunt is trying to get a job."

Participants identified parents as another source for information regarding students' experiences. One teacher shared:

I have found that families are willing to open up once they know me. It's a small community. So at this point, I've been in the school long enough. So all the kids and parents know me. So it's been easier to have them open [up]. Sometimes they even ask me for advice and next steps for their child.

Another commented: 
Parents, I think, are the same as kids. Once you have this open relationship, the more comfortable parents get with me. I always offer my cell phone or always meet with families whenever they need to [and] help them out whenever I could. Once you work with a family long enough, they don't mind telling you like, "Hey, I'm homeless right now, or we're staying a car," or they tell you about various situations. But again, I spend a lot of time trying to build rapport and trust with my students and families.

Participants also communicated they acquired information from other sources such as administrators, social workers, and other coworkers. They did not identify a specific system for getting that information. When directly asked if they obtained information from an administrator, the response was mostly the school counselor. Amy recalled how an entire team was developed based on a report for her student she would be receiving who witnessed a violent murder: "We had this huge meeting with our admin, [representation from the student's previous school], counselors, the social workers, everyone came.... We ran out of chairs."

Few referenced a plan of action to go with the information. Ben shared about a time he was informed that a sibling of a student was shot. No additional details or a plan of action was discussed. It was presented as information to know, and it was up to him to decide how to support the student. Chelsea shared, "The counselor will inform somewhat. I do not get as much information as I'd like, but I don't know what she's bound by either. It's a need-to-know basis."

Angie talked about the lack of understanding of her role in communicating with social workers: 
I have had social workers and CPS call before, and I didn't even know something was going on. [Sometimes] they want to interview the child. I didn't call, and I didn't know who called. I know there is confidentiality, but I feel like sometimes I need to know why they are here. Am I supposed to be looking out for something? When other coworkers shared information, it was often random and fragmented. One teacher shared how previous teachers would tell her information: "I think you should be aware of this or that.... This kid's mom is in prison, or this kid's mom died and just stuff like that." Another commented that she was not sure if the information she received from a colleague was accurate.

The data from the interviews pointed to the fact that educators in this study gained insight of the trauma students were exposed to from their students. It was difficult to establish any consistent systems across the participants of how information was acquired from administrators. One of the challenges for educators is not knowing about their students' experiences before they engaged with them. This can be a hindrance to the educators. They may be unable to prepare themselves for the students' potential behavior manifestations because of the exposure. This makes it difficult for them to minimize the impact of secondary traumatic stress because of the unknown trauma.

\section{Personal Impact of Working with Students Exposed to Trauma}

The purpose of this study was to gain insight into the living experiences of educators working with students who have been exposed to trauma. Using this data, I wanted to make meaning of these experiences and identify indicators that may signify teachers have been personally impacted by their work. The findings from this data indicate that educators working with traumatized students experience STS symptoms. STS 
characteristics are manifested in many ways. Dutton and Rubinstein (1995) categorize STS resulting from working with traumatized individuals to indicate psychological distress or dysfunction. Table 6 (Dutton \& Rubinstein, 1995, p. 85) summarizes the indicators and the symptoms that may be manifested.

\section{Table 6}

Indicators of Psychological Distress or Dysfunction

\begin{tabular}{ll}
\hline Indicators of STS & Symptoms of STS \\
\hline Distressing emotions & $\begin{array}{l}\text { Sadness or grief, depression, anxiety, dread and } \\
\text { horror, fear, rage, shame }\end{array}$ \\
\hline Intrusive imagery & $\begin{array}{l}\text { Nightmares, flooding, and flashback of images } \\
\text { generated during and following the client's recounting } \\
\text { of traumatic events }\end{array}$ \\
\hline Numbing or avoidance & Avoidance of things that serve as reminders of work \\
\hline Somatic complaints & $\begin{array}{l}\text { Sleep difficulty, headaches, } \\
\text { gastrointestinal distress, heart palpitations }\end{array}$ \\
\hline Addictive or compulsive behaviors & $\begin{array}{l}\text { Substance abuse, workaholism, compulsive eating } \\
\text { Physiological arousal }\end{array}$ \\
\hline Impairment of day-to-day functioning & $\begin{array}{l}\text { Absenteeism, chronic lateness, poor work } \\
\text { performance, quitting a job, decreased ability to } \\
\text { engage in self-care behaviors, feelings of isolation } \\
\text { and alienation }\end{array}$ \\
\hline
\end{tabular}

Participants in this study shared strikingly similar patterns as identified by these authors. Table 5 was used as an analytical tool to make meaning of the data from my interviews with elementary educators. It is important to note that this study focuses on the interaction between the traumatic experiences of their students rather than educators' direct exposure to student behavior that may appear to make them a primary victim. In other words, behaviors that manifest are likely a result of the student's own trauma, and 
those experiences become secondary for the educator. A student that has been directly exposed to trauma may become physically aggressive towards a teacher as a manifestation of the trauma. The educator is then thrust directly into a traumatic event. However, the purpose of this study the educator is secondary to the student's own direct experience of trauma.

\section{Distressing Emotions and Intrusive Imagery}

Paramount in the educators' responses were distressing emotions and intrusive imagery. Symptoms of STS for these markers revealed by the participants include anxiety, fear, dread, rage, and flashbacks of images generated as a result of interacting with their students.

Most participants struggle to hold back emotions while directly working with students. Kayla revealed several times during the interview the emotional toll:

"I get emotional every time I think about it."

"It broke me. I cried a lot."

"Crying on the way home because I can't let the kids see me crying"

Renee shared after an incident in which a student "destroyed the room":

I don't try to cry a lot at school. I save it for home. That day we had lunch right after that, and I cried. I know it was nothing that can't be fixed, but it's not okay. I had worked so hard to build a relationship with [the student]. I think that's what was so hard for me.

She went on to discuss another situation with a student that she described as "scary": He was one of my students from last year. He was the first kid that caused me to have a mental breakdown at school. Somebody had to cover my class, and that's 
never happened. I know it's only been three years [since I started teaching], but I thought I was good. I had never lost it at school.

Others spoke of the incredible fear that often encapsulates them after events unfold. Tiffany talked about being frightened by one of her students and concerned for other students' safety in her classroom:

The physical part really scares me because I've had a few kids in the past who have been fighters, and they want to get really physical and they get mad. I don't think they're going to hurt me, but they could. I mean, these kids are strong. Many of the educators also expressed dread and anxiety about the daily work of interacting with the students they serve. Ben reflected on recently learning that a student of his was having a difficult time. The student lost his brother and cousin on the same day to a shooting. Both were juveniles. Ben explained, "The thing is, it is constantly on my mind. So, I am constantly talking about it. You really feel helpless, like you can't do anything at this point. It just wears you down."

Others shared how learning of their students' exposure to trauma preoccupies their thoughts. They are often overcome with concern about the welfare of their students. Melissa recalled how long after the school bell rang, her thoughts and disturbing images of one of her students in which sexual abuse was suspected consumed her:

The thought that I was sending this child into a traumatic home, into an abusive situation, and I was going to go home and eat dinner. I was going [home] to my own children who were safe and treated fairly and wonderfully, while she was going home to a chaotic home and didn't know whether she was sleeping in fear. The urgency of that is, yeah, I can't control [anything]. I knew how slow CPS was 
in the past. I already had dealt with that before. So I was able to get the name of the CPS worker, and I called every day.

Kayla spoke of how knowledge of what her students experience triggered anxiety and concern within her:

I feel like this was even was more traumatizing: A teacher called me over and told me that one of my students found their neighbor dead under his car this morning while they were getting on the bus. I was like, "What do you mean? They're coming to school? They just found a dead body, and they're coming to school? And it was someone they know, their neighbor, who they talk to all the time?" I couldn't understand that. It would not process in my mind that two 10-year-olds and their little brother were about to walk into school after something like that.

\section{Physiological Arousal}

Educators spoke to the behaviors that were frequently manifested by some of their troubled students. Explosive outbursts included hurling objects around the room and striking students or staff. They spoke of having systems to mediate potential harm to other students and themselves. Tiffany recalls:

They [the students] were terrified. Even if he wasn't mad, if he came near them, they would jump or like lean over. There was one kid that was friends with him. But, he would also defend himself too because he was scared of him. And sometimes, I didn't know what he would do. So I was nervous about how he was going to react. He would kind of push off me. But I tried really hard not to let him see he was making me feel uneasy. If we needed to evacuate, we would do a signal. 
Melissa recalled troubling incidents in which she and other staff members have experienced physical harm:

If another kid's life is in danger of physical safety, I may have to step in. And on a lot of occasions, I have had to do that. But kids fight back, and they're big. So I have been scratched. I've been kicked. I've had blood drawn and had bruises and scratches and stuff like that. I had one [student] who took a security guard down. He got him down on the floor and grabbed the radio and threw it down the hallway, knowing that he couldn't call for help.

This constant state of alert and the educators' responses indicate they experience the STS physiological symptoms, including hypervigilance, difficulty concentrating, and irritability. Kayla shared her concerns for the safety of her students and others: I had another kid last year — he would forcefully bang his head against cinder blocks and duck his head and run full force into walls and doors, scream at the top of his lungs. But this is not what I went to school to do. I am not ... trained ... I don't know how to deal with this. I don't know what to do other than to call for ... we push the button and then SRT [school resource team] people come. So I have a lot of adults helping with that kiddo because it was not safe for him to be in a classroom. You never know what could ... like I said, sometimes their triggers are so off the wall sometimes, it's never consistent. I had to evacuate my class out of the room. Because there was no stopping him. He was throwing chairs, taking books off the bookshelf, trying to knock over my bookshelf and trying to go after other students and things like that. And again, I've never been trained on how to evacuate. I mean, obviously, we have active shooter training and things like that, 
but ... no class you're ever going to take in school is going to prepare you for one of your kids turning on you and throwing heavy things, not like it's paper balls or things like that, heavy weapons at this point, because it's [like] you don't know what's going to happen. So it's very much just always having to think ... I think that was probably the hardest part about dealing with that kid.

\section{Numbing or Avoidance}

A few of the teachers mentioned how they manage the feelings or thoughts about the knowledge of their students' experiences. This includes becoming numb to the constant barrage of information. Angie expressed:

Just sometimes, it's almost like ... I don't know if I might suppress some of that and just not talk about it. If you do not think about it for a while, then it did not happen, or you don't have to deal with it.

Kayla talked about the challenges of the anger she felt toward one of her students:

He was very secretive and manipulative. It's horrible to say about a 10-year old boy. There was a lot going on, and he was really nasty and hateful. It took a lot out of me to be nice to him. For a lot of times, to cope with it, I did the unhealthy part and just turned it off. Just didn't think about it. Because I was tired — I was just mentally exhausted about always having to think about him constantly in the back of my head for nine months out of the school year was hard. I didn't think it was fair to me to have to think about it after school.

\section{Somatic Complaints}

The impact on educators also has a physical aspect that involves somatic concerns. Dutton and Rubinstein (1995) characterized this as sleeplessness, headaches, 
gastrointestinal distress, and heart palpations. In this study, educators also expressed somatic complaints that range from the inability to sleep or neglect of personal well-being, to seeking medical care and diagnoses.

Melissa revealed that she has trouble sleeping. "There is one that I lost sleep over — well, there are a lot of [students] that I lose sleep over."

Chelsea shared that she did not sleep well and was constantly working. She spoke of how she neglected her health, including missing doctor appointments:

Honestly, I don't do very well taking care of myself. To give you a really good example, I was diagnosed with breast cancer. I would say that in the beginning, doctor's appointments, things like that, I would put off. I was more concerned with how my students might act with a sub. It just wasn't worth the loss and trying to get them back on the same page when you return.

She goes on later to declare how excessively tired she is daily. She noted that the symptoms of STS resonated with her, and it was a determining factor for her to participate in this study.

Ben talked about having high blood pressure and being overweight due to stress: You're hit, and you're cussed [at]. I went to school to be an educator. I loved education. But because of the stress that I am under from beginning to end, I just can't deal with this. You're dealing with fires all days. It does affect us.

\section{Addictive or Compulsive Behaviors}

Most troubling is the impact on educators leading to addictive or compulsive behaviors. Melissa attributed her work as a contributing factor to her downward spiral with alcohol: 
So the anger just overwhelms me when I think about somebody doing something to a kid. There were a lot of emotions for the first six years. It led to me drinking more alcohol than I should in the evening time to the point where I did seek help on the outside for that and quit altogether.

Susan shared that she would go home and have a drink more nights than not.

Chelsea admitted that she is constantly working in hopes of making a positive impact in her students' lives: "I work more than I ever have. Literally, 9 to 9."

Susan talked about how she finds herself working all the time to try to "fix the brokenness" in the lives of her students:

I was the brokest first-year teacher. I brought kids sweaters, sweatshirts, and hats. The things you can fix, I will fix. I will make sure you have dinner. I will call and get you assistance with your facilities or whatever it is [you need]. I just try to fix everything, which is incredibly difficult, and time-consuming, and exhausting. When I begin to worry about it, I don't sleep. The stuff like physical and sexual abuse, I think those were the hardest because there was nothing I could do to fix it [fast]. I can't go to Walmart and buy something to fix that.

\section{Limited Resources}

Several educators expressed concern that they often lack resources or support. Melissa commented that she realized at one point that the district had nothing in line to help teachers with the most challenging students. Chelsea talked about a time when a student was in the throes of an emotional breakdown. She wanted to talk with the student and help him through the feelings he was experiencing at the time, but the reality was that she was in charge of 20 other students at that time and could not dedicate the time to 
comforting the student who was obviously in distress. She recalled being frustrated by the response she got from an administrator when she called for help:

I remember calling for the counselor in the hallway and saying, "Could you please pull him some time? He is really struggling." I explained what was happening in his life. I was just told they were busy, and they would try. That has stayed with me all these years because I just cannot imagine anything being more important than what was happening to that little boy right there. I tried my best, but I had no instructional assistant or anybody in the room with me at the time. I've got 24 kids, this poor little boy is struggling, and I'm trying to balance a way that I can be his mental counselor while keeping a class engaged and doing something. A lot of it is a lack of resources. I'd say that's a huge part. I don't want to sound callous, but at times it would sound like we were in One Flew Over the Cuckoo's Nest. You feel like you are working in an insane asylum. Kids out in the hallway not just screaming but just almost primal. Feral. Just gut-wrenching, screaming, and pain. Those are the things that really get to me. It just shakes me for the day or two or three. When kids are so out of control like that and have to be put in a hold and watch them, $[\mathrm{I}]$ just try so hard to calm them down, so they wouldn't have to be put in a hold. Just not being able to do that was upsetting to me. So many of our kids would go in and out of the hospital.

Kayla also talked about the challenges of not being able to access support for her students:

I just wish there were more resources available for parents and families, and teachers when we are put in situations like this because you get to the 
point where it was getting difficult to get a hold of mom, and the school would be like, "If you don't answer the phone, we have to call an ambulance." Because it was not normal to have this [explosive behavior] just because I told him he needed to do something.

\section{Impact on personal relationships with family}

Numerous participants revealed the impact of working with students who have been exposed to trauma on their personal relationships with family. The complaints included difficulty balancing family responsibilities with work and the ability to engage. Some communicated that it has had a significant impact, including withdrawing from family members and divorce. Melissa shared how her experiences led to conflicts at home:

The longer I work with [my students and the neighborhood the more protective I am to] their families and the community. So we [ex-husband] clashed with our [viewpoints]. I had a sense of compassion, and he had a sense of coldness about them and the community. There wasn't anyone to really share. No one understood, and [a] lot of family would say, "Why are you still there? When are you transferring out? When are you getting out of there?" I would hear comments like that. So that again was kind of a beat down. I thought, "There's no one who is impressed with what I do." It was a disconnect, and I did kind of realize at one point that I just can't talk to anybody about it except my people at school.

She went on to acknowledge that this kind of disconnect and resentment was an aggravating factor that ultimately led to her divorce.

Chelsea talked about the difficulty she had getting people to relate or understand why she chose to continue teaching at her school: 
I don't think people are aware until you come into this district and work in one of our high-risk schools that children are hospitalized for mental [illness]. It never would have occurred to me in a million years that an ambulance will come and take a little child away. But they do, and they do it more often than anybody would want to know happens. At first I would say, "No, working here does not impact my ability to connect to my family and friends." My family, my parents, my sister, my brother, lots of friends will say, "You need to go somewhere else. All schools are not this way." When I tell them some of the stories, they want to blame the parents or blame the children. One of my close friends used to work here, but she left. I stay in touch with her, but I don't talk to her as much about this because she moved on.

Angie shared how her husband would complain about how she talked to him and her inability to tamper down the day's frustrations when she returned home from work. She acknowledged how hard it was to engage her toddler on some days:

The fuse is shorter when it's been lit all day long, and you're tired. And you're just like, "I don't want to play with you right now." And then you feel the mom guilt. But I just can't. So I tell him to play with your toys, or I give him something he enjoys doing alone.

\section{Coping Strategies to Support Teachers}

\section{Relationships}

All participants referred to relationships with their school communities as a mediating factor to help them cope with the challenges of working with students exposed to trauma. Relationships with colleagues, students, and families strengthened their ability 
to cope with day-to-day interactions. Susan shared that she feels a particular bond because she resides in the same location as the school.

Participants were probed on whom they talk with about the challenges they face. All communicated that they depend on coworkers to confide in about the difficulties of working with their students. Angie shared:

It's very common to congregate [with coworkers] especially after school and just be like, "This is what so-and-so did today. I'm feeling this sort of way." That usually turns into a, "Well, tomorrow, let's try this." That's what I love about our teachers. We have each other's back.

Kayla talked about the connection she has with her coworkers: "I know, for me, I am close with my teammates. If I ever need to talk about something with them, it's easy for me to do."

Susan spoke about the lasting relationship she has with former coworkers and how that bond continues long after they have left the school:

I have my different groups of teacher friends. I have the ones that are still at [my school] those that have gone. We are all still connected, but they are no longer directly involved. I can talk to them openly because they don't know these people and they're kind of removed. They can offer me insight from a different viewpoint.

\section{Self-Care}

Participants in this study were asked how they balance the demands of working with students who have experienced trauma. Many noted that the longer they have stayed at their schools, the more equipped they become in practicing self-care. 
Renee shared that she had to shift her thoughts and actions to take care of herself intentionally:

I have learned a lot in the past year or two. I cannot work constantly. I think that is a common theme among teachers - you just work constantly. You go home on the weekends, and you work all weekend. I have realized it doesn't matter if I work all day — there is still going to be work to be done. I need to take at least a day off during the week and just relax. And I have given myself a lot of grace with that the past two years. I just need to chill out. It's not going to be perfect all the time. So if I have a bad day, I have learned to come home and not get on my computer. Don't do anything school related, do something that's fun for me, take a nap, take a bath, go out to eat, whatever sounds good to me. And it really does help. It sounds so silly to be [like], "Well, this is self-care Tuesday or self-care Saturday," or whatever, but it does help me to just put all my work aside.

Angie also talked about the importance of taking time out:

I try to get enough sleep. I don't stress myself out like some of my colleagues [by] staying up to midnight doing stuff. I'm just like, how do you function at 7 in the morning then? That's the biggest one. And then the other one is I don't spend my lunchtime making copies hardly ever. I need to spend even if just 10 minutes in the teachers' lounge and eat a snack just to take a quick break from that.

Incorporating exercise and healthier eating were common strategies implemented by many of the educators. Melissa shared how she came to focus on improving her health: Self-care has been exercise because I want to be better for them [students]. I have had students with asthma and just on the verge of type 2 diabetes and everything 
else. And I thought this was going to my thing with them. When I'm on the playground, I'm going to run. I'm not going to stand there and talk or whatever. So my self-care has become a physical thing. I can't run as much anymore, but I ride bikes, and I work out. That's probably my biggest release.

Both Ben and Amy shared how they took on the responsibility of adopting a pet to help them become more active. Others have learned to practice mindfulness and think positive thoughts. Ben spoke to how he uses his positive outlook to support others:

I try to stay away from negative energy. I like to keep everything positive around me. I try to have a good personality, my sense of humor, and I'm always smiling so people feel comfortable when they come to me. I don't give much advice, but I am someone who will listen.

\section{Sense of Fulfillment}

Several participants spoke about the sense of fulfillment that keeps them grounded at their school location. Amy shared:

I was just talking to a coworker about how everyone leaves. I just feel like because everyone leaves, these kids don't really have a stable person in their life if you think about it, sometimes at home too. So I guess I'm kind of like emotionally invested. I love being there. I just feel like I do sometimes make a difference. I mean it might be a small difference. ... I see so many positives in our kids. I think they are amazing and so smart. I guess I see things that other people don't.

Renee commented on the connection she has with her colleagues:

I have a really, really good solid group of friends at school who, when something happens, I normally will go to them. They are really good listeners, and they just 
make me feel better. So I know who to go to when it gets hard.

Kayla talked about her commitment to the students she serves:

I would rather deal with kids who have experienced trauma and try to help them in whatever way that I can. Like I said, I'm not trained to do this. I have no idea if I'm even leading them in the right direction. But I know there are teachers who are not as willing to take the extra five minutes out of their day to try and understand what the problem is. And I would rather be that person for them, who they know that they can come to and they know that they can talk to or whatever. I would much rather be in a position to where I can actually make a difference in someone's life, than at say another school where it's more about volunteering at the bake sale or things like that. I love my school, I love my kids, and I love my families. It's definitely way, way, way more challenging than a lot of schools and a lot of students. But I know from my own personal experiences and from my friends who are at different schools and parents who have kids at different schools, how some teachers are very quick to just dismiss something as a behavior problem and not look into it or not try and do that. I don't like when kids get swept under the rug, and when kids get mislabeled as the bad kid because something's happening that no one's trying to find out about.

\section{Nurturing Those that Nurture Others}

When probed, most participants commented that they had never been cautioned about the potential of being exposed to secondary trauma. Nearly all of the participants confirmed that there were no systematic supports in place at their school locations to address the issue. They discussed professional development that has been provided around 
trauma-informed care. The goal was to provide educators with tools to support students that have been exposed to trauma. However, there was little to no mention of what the educators could do to take care of themselves.

Many expressed excitement about this research. Susan ended her interview by stating:

I don't have anything else to add except I'm just happy that you are taking a look at this. I think this is important work. I think so many new teachers come in like I did. I was aware that things like this would pop up; I didn't have any idea of how frequently they would occur.

\section{Summary}

The evidence presented in the section gave voice to the lived experiences of educators working with traumatized students. Educators acquired information in various ways; however, students were the primary source for disclosing their trauma. They discussed the types of exposure that their students faced, including how they manifested in the classroom.

Educators also provided detailed descriptions of the personal impact the exposure of learning has on them. The data collected suggest educators suffer from STS similar to those in other professions such as first responders and social workers. The data from the interviews identified indicators of psychological distress or dysfunction.

The educators shared how they cope with the challenges of working with traumatized students. Relationships are a common theme among all of the information presented. Those educators who were able to build a community with colleagues and/or students and families seem to manage the exposure. They also discussed self-care and the 
obstacles to maintaining their welfare. Implications for practice and recommendations for future research will be discussed in the next chapter. 


\section{CHAPTER V \\ DISCUSSION}

\section{Introduction}

This dissertation study aimed to explore the lived experiences of educators working with students who have experienced trauma. The study provides a voice to educators' experiences to identify the cost levied for providing emotional support to students in their care. More importantly, I desire to sound the alarm for educators in a similar manner that has been afforded to others that work with traumatized individuals. Semi-structured interviews were conducted with each participant, and the data was analyzed according to the research questions. The findings were presented in Chapter IV. This concluding chapter will present a summary of the study, discuss key conclusions identified from the data and implications for the education community, as well as recommendations for future research.

\section{Summary of the Study}

The purpose of this study is embedded in the three guiding research questions. The first was to recognize the experiences of elementary teachers working with students who have been exposed to trauma. The second was to identify how the experiences influence the educators. Thirdly, the objective was to explore how teachers cope with and process their experiences of working with traumatized students.

In Chapter I, the modern schoolhouse is presented, along with an overview of the 
growing number of students who come to school saddled with physical and emotional baggage. According to the National Center for Mental Health Promotion and Youth Violence Prevention (2012), 26\% of children in the United States will witness a violent act or directly experience a traumatic event before they turn 4. These experiences can have a devastating impact on the children. Children who are repeatedly exposed to traumatic events can have impairments in their ability to interact with others, including teachers and peers (Ko et al., 2008). The chapter introduces secondary trauma and the potential influence it can have on educators supporting these students. The final section of this chapter establishes the purpose of this study and its scope.

Chapter II reviews literature to define secondary traumatic stress and similar constructs. Secondary trauma/secondary traumatic stress is identified as the natural consequential behaviors and emotions resulting from knowledge about a traumatizing event experienced by another (Figley, 1995). The chapter also explores the literature on secondary trauma and the helping professions. It reveals the limited research on how this construct influences educators. Chapter II also establishes the contextual settings for urban schools and how they serve as a host for larger populations of students who have been exposed to trauma. Similar to other professions that work with traumatized individuals, educators are potentially impacted by secondary traumatic stress.

Chapter III focused on the methodological approach selected for this research study. This qualitative study used a phenomenological inquiry design and was conducted in a large urban public school district in the United States' southeastern region. Participants were educators recruited from seven elementary schools, with $90 \%$ of the student population qualifying for free or reduced meals. The educators self-identified as 
having experienced secondary trauma. The chapter concluded with an overview of the data collection and analysis process and ethical considerations.

Chapter IV presented a summary of the research findings from the data collected from the participant interviews. Finally, Chapter V will discuss the three research questions and the conclusions drawn from the research.

\section{Discussion of Findings}

Research Question 1

How do educators acquire information about their students' traumatic experiences?

Educators who participated in this study serve in six of the eight schools in the district with $90 \%$ or higher of the student population qualifying for free or reduced meals. Children who live in more impoverished communities are frequently exposed to danger (Evans, 2004). High-poverty schools are met with the challenge of serving far more students who have been exposed to trauma than their counterparts (Anderson et al., 2015).

In this research study, elementary teachers' lived experiences working with students exposed to trauma were explored. During the investigation, participants shared the sobering reality of the types of trauma inflicted on their students. All spoke of the weight of poverty and the trauma that is enacted when students do not have their basic needs met. Literature in Chapter II of this study indicates that students living in highpoverty areas are more likely to be exposed to traumatic events (Buka et al., 2001; Hurt et al., 2001; Kiser, 2007). The teachers shared that many of their students were all too familiar with the sounds of gunfire and the tragedy of losing family members as a result. 
The educators shared the angst they often feel as they try to console their students. In some cases, the children have been separated from their parents due to incarceration, and they bear the scars of abandonment. Others have physical scars that are the result of abuse or neglect.

Teachers spoke of the challenges of engaging students while they are suffering from traumatic experiences. One teacher recalled a time when one of her students and his siblings arrived at school immediately after witnessing a devastating event that led to a neighbor's death. Her emotions were still raw during the interview, remembering the difficulty she had in maintaining her composure, knowing what her students just saw, and the frustration that they were sent to school: "They weren't even allowed to grieve." Another shared her ongoing concern for a student whom she suspected was being sexually abused. Each day, she said she looked for signs that the little girl was okay and had survived another night of "God only knows what." This type of intrusive imagery is a common concern for those who work with traumatized individuals (McCann \& Pearlman, 1990; Pearlman \& Mac Ian, 1995; Bride, 2007).

The potential consequences of trauma in young children can lead to extensive disruptive behavioral responses (Shonkoff \& Garner, 2012). Participants spoke of the explosive behavior that students manifest as a result of their experiences. The educators shared the various strategies and techniques they institute to ensure student safety. This includes taking drastic measures to ensure student safety. Ben revealed:

All of the desks are zip-tied to each other. So a kid can't just push his desk over because his desk is zip-tied to the desk beside him. If they want to knock it over, they can push it up, but it does not go far because it is connected to nine other 
desks.

A heightened sense of anxiety of the unknown and the inability to protect their students was a common theme from each of the educators interviewed. Pearlman \& Saakvitine (1995) point out that the risk of STS is more significant when there is an emotional and physical response from the traumatic individual.

\section{Research Question 2}

How do the lived experiences of elementary teachers working with students who have been exposed to trauma influence the educators?

Empirical literature exists that shows secondary traumatic stress is an occupational hazard for social workers, first responders, and other similar professionals who engage with traumatized individuals (Bride, 2007; Dominguez-Gomez \& Rutledge, 2009; Sprang, Craig, \& Clark, 2011). Dutton and Rubinstein (1995) identified seven indicators of STS. They include distressing emotions, intrusive imagery, numbing, somatic complaints, addictive or compulsive behaviors, physiological arousal, and impairment of day-to-day functioning. Using the Dutton and Rubinstein construct as an analysis tool for this study, themes from the data emerged from the educators' lived experiences. The results were striking parallel to the work illustrated in the research among social workers and other professionals who work with the traumatized. This is further discussed in the next section.

\section{Distressing Emotions and Intrusive Imagery}

One indicator that was paramount among the educators was being overwhelmed and the feeling of helplessness in meeting their students' needs. Most expressed that they were unaware before serving in an underprivileged school of the sheer volume of 
students exposed to violence. Several admitted that there had been times when students and families revealed experiences that left them worried and concerned for their wellbeing.

The constant barrage of traumatic experiences presented to the educators affects them and impairs their personal well-being. This was consistent with the research that points to evidence of the impact of intrusive imagery among those working with the traumatized (Bober \& Regehr, 2006; Bride, 2007). All of the educators revealed that events sometimes replayed in their minds and left them emotionally overwhelmed. Most shared that the inability to turn off the powerful images was distracting. As a result, there were times that they were not able to disconnect from work and engage with family and friends. Tiffany talked about the disturbing thoughts that kept her worried about one of her students' safety over the winter break.

Others discussed how the interactions brought back memories of their own difficulties in their personal lives. When a student expressed emotions after being separated from her parent due to incarceration, Kayla recalled the memory of her dad leaving her home following divorce from her mom. She shared how all of the fear and anxiety came flooding back. Individuals with personal trauma have been examined as a predictor for STS among trauma workers (Pearlman \& Saakvitne, 1995). The researchers noted that those with their own history of victimization hear clients' stories and feelings and then are reminded of their own abuse or neglect. Kayla went on to disclose how she relived the pain of abandonment, and those images haunted her, worrying about the loneliness and shame her student was feeling. 


\section{Physiological Arousal}

Many of the educators in this study revealed that they have at times feared for the safety of themselves or other students in their classroom. Melissa, Kayla, Ben, and Emily all talked about having students engage them physically in an attempt to cause harm. All discussed systems they have established to call for help or evacuate the classroom in the event a student becomes hostile and is unable to be deescalated. Ben shared his passion lies in working with the students and families in his school. Unfortunately, he also stated that his departure from the profession is imminent. The constant stress of dealing with the lack of resources to support students and the behaviors that manifest from trauma has been more than he can see continuing to endure. At the time of the interview, he referenced that he would likely be leaving the profession at the school year's close to pursue other endeavors.

\section{Numbing or Avoidance}

Numbing or avoidance is another indicator that is commonly associated with secondary traumatic stress (Dutton \& Rubinstein, 1995). Bride (2007) provides descriptors for avoidance, including diminished activity, avoidance of clients, and an inability to recall client information. Some teachers in this study reported that they avoided or suppressed feelings to manage the emotions or anxiety associated with learning about their students' traumatic experiences. Angie revealed that she forces herself not to think about certain situations: "If I don't think about it, then I can convince myself that it didn't happen. This helps me to keep going every day.”

In a 2009 study of secondary traumatic stress among emergency nurses, 52\% reported avoidance symptoms (Dominguez-Gomez \& Rutledge, 2009). Fewer 
participants in this study identified behaviors consistent with this symptom. The criteria for selection for this study were that participants must have served in the school for a period of time. It could be suggested that those who may have experienced avoidance or numbing may have taken another school assignment or left the profession altogether to avoid working with these traumatized students.

\section{Somatic Complaints}

Participants in this study discussed the toll on their physical health that is brought on by the stressors of working with traumatized students. Chelsea and Ben talked about the negative medical reports they received. Stress is an aggravating factor to these conditions, and they expressed the difficulty of trying to manage their illness in a highstress environment. Melissa, Ben, Kim, and Kayla shared that they intentionally incorporated activities such as exercising and getting more sleep to improve their health.

\section{Addictive or Compulsive Behaviors}

Dutton and Rubinstein (1995) identified workaholism and substance abuse as examples of how secondary traumatic stress may manifest in those working with the traumatized. The teachers in this study revealed some of their challenges. All of them mentioned the trials of seeking to find solutions to their students' crises. Some discussed how they spent extra time in the evenings or on weekends providing individualized support to students. Ben referenced that he stays in contact with students long after he has had them in his classroom and they have transitioned to other schools. Kim talked about the concern for her students that leads her to work endlessly: "I am so concerned about the safety of some of my students. I try to make sure they have what they need." Many shared that they provide parents with their personal cell phone numbers to reach out if 
there is ever a need.

All of the educators in this study revealed that, at times, their work has become overwhelming to the point that it has negatively affected their personal lives. Melissa and Angie shared examples of conflict at home when they interacted with loved ones destructively due to stress or tiredness. Many of the participants shared that, at times, they felt a sense of guilt because they were not able to regulate emotions once they got home. Ben talked about his short fuse after holding it together during the workday. Sadly, some educators also disclosed that they had turned to unhealthy habits such as drinking and overeating as coping mechanisms. Several were candid about their experiences with alcohol as a means of coping with the knowledge and demands of working with traumatized students. One participant spoke of seeking professional help when the compulsive behavior became too much to overcome.

\section{Research Question 3}

How do teachers cope with and process their experiences of working with traumatized students?

The literature review in Chapter II of this study explored the existing research on how those impacted by secondary traumatic stress manage and cope with their experiences. Skovholt and Trotter-Mathison (2016) highlight the importance of those serving in helping professions to continue to maintain professional vitality and avoid depleting caring. They go on to note that for teachers, this can be a difficult task.

The research literature in Chapter II also explored activities that educators can use to manage self-care. Hydon et al. (2015) investigated a research-based program developed in partnership with The United States Department of Education. School districts in New 
Orleans following the Katrina aftermath provided workshops to support educators in those communities. The program identified six areas to engage and promote self-care. Those areas include social, physical, intellectual, financial, spiritual, and financial well-being. Participants in this study were asked how they balance the demands of working with students who have experienced trauma. Many noted that the longer they have stayed at their schools, the more equipped they become in practicing self-care. Some familiar themes from the literature review in the areas of social, physical, intellectual, and environmental self-care were expressed during the interviews.

\section{Physical Self-Care}

Nearly all of the teachers credited their ability to continue serving in their current school assignments to intentionally making the decision to take care of themselves. Some shared that they take time to get proper rest by getting to bed earlier or taking breaks as a means to improve their overall dispositions. Others talked of designating family time and purposely releasing or turning off work-related distractions. Hill (2011) cited similar findings in which participants shared the importance of adequate nutrition, exercise, and rest as essential factors in managing self-care.

\section{Social Self-Care}

All of the teachers in this study spoke highly of their reliance on colleagues for support. They talked of seeking sustenance from colleagues for emotional backing. When probed about formal structures that encourage this communication, many responded that it was not established, but they would favor having this type of support. 


\section{Intellectual Self-Care}

Several participants identified ways they are stimulated intellectually by attending workshops, actively get involved in social action committees, or taking on new hobbies. Melissa shared that she was active in her professional association. She regularly attends workshops focused on particular topics that promote social justice. These activities have helped her be more informed about the needs of her students. Melissa also spoke of the camaraderie she feels with other teachers who serve on these committees and how she now feels she is not alone in her daily struggles.

Ben shared his excitement about taking on a new business venture. It started as a hobby working part-time on a pastime that he has enjoyed since his childhood. He spoke about how this outlet has helped him to be more relaxed.

\section{Environmental Self-Care}

Several participants spoke of surrounding themselves in space outdoors as a means to recharge. Jerome talked about meeting friends at the park to unwind as a way he routinely let off steam. Melissa enjoys outdoor recess as a time to release while connecting with her students.

Collectively, most of the educators were able to voice how they coped with the effects of the environmental factors in which they work, although there was evidence that at times they struggled to manage the impact. Based on the themes that have emerged, systemic efforts should be engaged to provide proactive ways to support educators.

\section{Implications for Practice}

Despite recent research to bring awareness of STS among educators to the 
forefront (Hydon et al., 2015; Hill, 2011), this study adds to the body of evidence that minimal traction has occurred in terms of training and support to educators.

Many educators in this study revealed they often feel their own personal health and welfare are not considered by their administrators or district. Both Ben and Melissa shared how they kept waiting for someone to help their schools and address the daily crises they see. Melissa shared, "It's like they have nothing to offer us." All of the educators shared that very few resources exist for them to turn to address their personal well-being. Several stated that the interview for this study was the first time anyone had given them an opportunity to communicate their thoughts about their experiences.

Chelsea, Melissa, and Jerome revealed they had never considered that they had been impacted by STS until the recruitment letter. Jerome stated that he had not heard the term as a potential occupational health risk associated with educators. Melissa said that while her school is identified as a trauma-informed school, the primary training has been centered around the students' needs. She recalled a brief session in which secondary trauma and self-care were mentioned; however, she admitted that she never felt like that pertained to her during the session. It was not until this research recruitment information for this study was shared and examples of what STS could look like were presented that she genuinely felt that she identified with this trauma.

Participants in this study acknowledged that they knew there were things in the workplace that negatively influenced their personal well-being. What is striking is nearly all of them indicated that no one had attempted to give a name to the potential hazard of STS, much less a venue and resources for managing it. This evidence should serve as a rallying call to support educators. It is imperative that teacher preparation programs 
incorporate into their curriculum an awareness of STS as a potential hazard in the teaching occupation and equip teacher candidates with ways to mediate personal harm. Preservice professional development in school districts should also include an awareness of this issue and supports.

In Chapter II, the ecological model (Figure 2) for preventing secondary traumatic stress (Yassen, 1995) was discussed. This model provides a comprehensive approach to highlight the interaction of the individual and environmental influences that can mediate or prevent the onset of secondary traumatic stress. Importantly it illustrates that the individual alone should not be expected to manage their self-care. There are opportunities for employers - in this case, school districts - to support educators in preventing STS. This study's findings shed light on coping factors that the educators utilized to support them in managing STS. The participants also exposed some of the environmental factors that served as contributing factors to the crisis. 


\section{Figure 2}

Ecological Model for the Prevention of STS

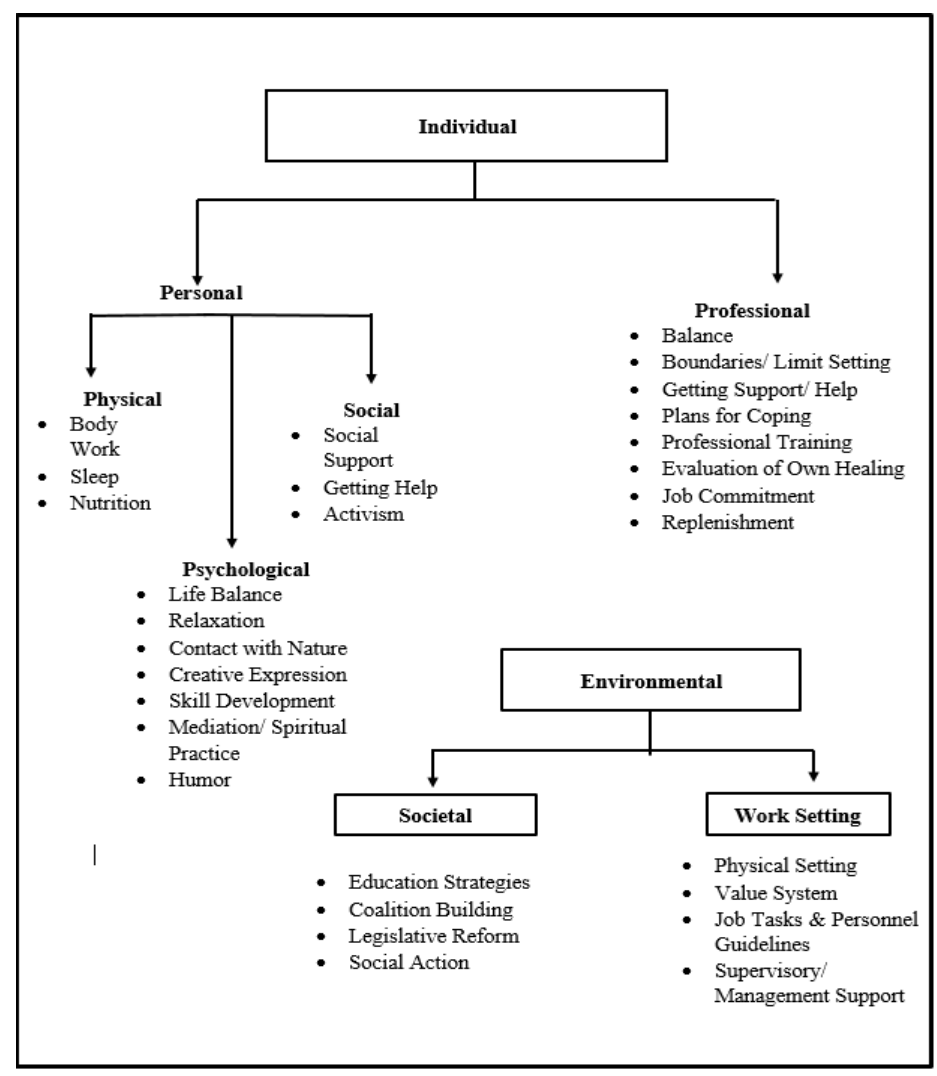

Note. From: Ecological model for the prevention of STS Yassen, J. (1995). Preventing Secondary Traumatic Stress Disorder. Compassion fatigue: Coping with secondary traumatic stress disorder in those who treat the traumatized

The educators spoke of the overall volume of students who have been exposed to trauma. Many shared concerns that their schools were not adequately resourced to meet those needs. They believe it is important to have additional mental health counselors and other supports to meet the demands of students in need. Currently, the district funds one mental health counselor for each school and does not consider that some schools have a higher concentration of traumatized students. By ensuring schools are sufficiently allocated the appropriate resources, secondary traumatic stress towards the educator can be mediated and support the individual needs of traumatized students. This, in turn, can help 
build a positive school community.

Teachers in this study talked about informal steps they took to intercede the emotional stress they felt from working with traumatized students. All of the participants expressed that they found solace in talking through their experiences with others. Appropriate structures should be put in place that educators can use to solicit assistance. This could include ongoing teacher support groups and access to professional counseling. Mindfulness workshops and promoting decompression activities to manage stress in a healthy way are excellent opportunities to offer educators at individual schools.

\section{Recommendations for Future Research}

Despite recent efforts to bring awareness of STS among educators to the forefront, this study adds to the growing body of evidence that minimal traction has occurred in terms of training and support to educators. As with most qualitative studies, the sample size in this study was small. Ten teachers from six schools participated in this study. Creswell (2014) points out that qualitative studies are not intended to be generalized. In this regard, additional studies should be conducted to add to research in this area. Replicating this study with additional educators could further establish the impact of secondary traumatic stress on those that educate traumatized students.

In addition, future research should explore the organizational systems that mediate secondary trauma among educators. Pearlman and Saakvitne (1995) identify organizational strategies that can be employed to support those working with traumatized individuals. Future researchers should investigate the demands on educators, such as the number of students they serve, resources available to assist students, and other organizational barriers that can cause harm to teachers. 
Finally, Pearlman \& Mac Ian, 1995 discusses the connection between personal trauma experienced by the helper as a catalyst for being at a greater risk for secondary trauma. Future research should explore this area as another potential indicator to increase educators' awareness of the increased risk.

\section{Closing}

The courageous educators who participated in this study were willing to bring a voice to elementary educators' lived experiences of working with traumatized students. They candidly discussed the impact of their personal well-being as a result of serving their students. The teachers also expressed passion for the work they do. All spoke to their desire to make a difference in the lives of students in their schools. They know the challenges the students and families are up against, and they want to be a resource to mediate those hurdles.

The school district has already transitioned to increasing awareness of secondary trauma by acknowledging that it exists and reminds educators of the importance of selfcare. However, there is still much to be done. Bell et al. (2003) discuss the role organizations have in preventing secondary traumatic stress with the following:

The values and culture of an organization set the expectations about the work.

When the work includes contact with trauma, they also set the expectations about how workers will experience trauma and deal with it, both professionally and personally (pp. 445-446).

The findings in this study identified themes that are similar to research studies that have explored secondary traumatic stress. This research can support teacher preparatory programs and school districts in training on educating teachers on this topic. These 
organizations must educate those that are currently supporting traumatized students and bring awareness to this occupational hazard. Taking a proactive approach could help those who may not understand the devastating impact STS can have on them. One participant in this study closed out her interview with this:

What strikes me about this interview is the fact that there are people now you're evidence of that — that are researching this [secondary trauma among educators]. So, they don't just throw the term at us and go. They can help us figure out what to do about it. I wonder how many teachers it has affected. I've just survived it for whatever reason. I wonder how many teachers would have stayed if someone would have helped them understand what was going on. Instead, we have teachers that are going home and drinking or going home feeling guilty or dealing with anxiety. I'm glad to know that there's research going on out there to help us.

With this awareness, it is my hope that educators will be empowered to continue serving their students while protecting their own well-being. 


\section{REFERENCES}

Abel, M. H., \& Sewell, J. (1999). Stress and burnout in rural and urban secondary school teachers. The Journal of Educational Research, 92(5), 287-293.

Alim, T. N., Graves, E., Mellman, T. A., Aigbogun, N., Gray, E., Lawson, W., \& Charney, D. S. (2006). Trauma exposure, posttraumatic stress disorder and depression in an African-American primary care population. Journal of the National Medical Association, 98(10), 1630-1636.

Alisic, E., Bus, M., Dulack, W., Pennings, L., \& Splinter, J. (2012). Teachers' experiences supporting children after traumatic exposure. Journal of Traumatic Stress, 25(1), 98-101.

American Psychiatric Association. (2020). Helping professions. Retrieved March 16, 2020, from https://dictionary.apa.org/helping-professions.

American Psychiatric Association. (2013). Diagnostic and statistical manual of mental disorders (5th ed.). Arlington, VA: American Psychiatric Publishing.

Anda, R. F., Felitti, V. J., Bremner, J. D., Walker, J. D., Whitfield, C., Perry, B. D., \& Giles, W. H. (2006). The enduring effects of abuse and related adverse experiences in childhood: A convergence of evidence from neurobiology and epidemiology. European Archives of Psychiatry and Clinical Neuroscience, 256, $174-186$.

Anderson, E. M., Blitz, L. V., \& Saastamoinen, M. (2015). Exploring a school-university model for professional development with classroom staff: Teaching trauma- 
informed approaches. School Community Journal, 25(2), 113-134.Baird, K., \& Kracen, A. C. (2006). Vicarious traumatization and secondary traumatic stress: A research synthesis. Counselling Psychology Quarterly, 19(2), 181-188.

Bernard, H., \& Ryan, G. (2010). Analyzing qualitative data: Systematic approaches. Los Angeles CA.: SAGE.

Best Start Resource Centre. (2012). When compassion hurts: Burnout, vicarious trauma and secondary trauma in prenatal and early childhood service providers. Toronto, ON: Author.

Betts, J., Zau, A., \& Rice, L. (2003). Determinants of student achievement: New evidence from San Diego. Public Policy Institute of California, 1-139. San Francisco: Public Policy Institutes of California.

Bevan, M. T. (2014). A method of phenomenological interviewing. Qualitative Health 706 Research, 24(1), 136-144. doi:10.1177/1049732313519710

Bober, T., \& Regehr, C. (2006). Strategies for reducing secondary or vicarious trauma: Do they work? Brief Treatment and Crisis Intervention, 6(1), 1-9.

Borg, J. R., Borg, M., \& Stranahan, H. (2012). Achievement gap between high-poverty schools and low-poverty schools. Research in Business and Economics Journal, $5,1-24$.

Breslau, N. (2002). Epidemiologic studies of trauma, posttraumatic stress disorder, and other psychiatric disorders. The Canadian Journal of Psychiatry, 47(10), 923929.

Bride, B. E. (2007). Prevalence of secondary traumatic stress among social workers. Social Work, 52(1), 63-70. 
Briere, J., \& Jordan, C. E. (2009). Childhood maltreatment, intervening variables, and adult psychological difficulties in women: An overview. Trauma, Violence, \& Abuse, 10(4), 375-388.

Bronwyn, B. \& Suniya, L. (2002). Social-emotional factor affecting achievement outcomes among disadvantaged students: Closing the achievement gap. Educational Psychologist, (4)37, 197-214.

Buka, S. L., Stichick, T. L., Birdthistle, I., \& Earls, F. J. (2001). Youth exposure to violence: Prevalence, risks, and consequences. American Journal of Orthopsychiatry, 71(3), 298-310.

Carlson, E. B., \& Dalenberg, C. J. (2000). A conceptual framework for the impact of traumatic experiences. Trauma, Violence, \& Abuse, 1(1), 4-28.

Child Welfare Information Gateway. (2013). What is child abuse and neglect? Recognizing the signs and symptoms. Washington, DC: U.S. Department of Health and Human Services, Children's Bureau.

Cloitre, M., Stolbach, B. C., Herman, J. L., Kolk, B. V. D., Pynoos, R., Wang, J., \& Petkova, E. (2009). A developmental approach to complex PTSD: Childhood and adult cumulative trauma as predictors of symptom complexity. Journal of Traumatic Stress, 22(5), 399-408.

Cole, S.F., O’Brien, J.G., Gadd, M.G., Ristuccia, J., Wallace, D.L., \& Gregory, M. (2005). Helping traumatized children learn: Supportive school environments for children traumatized by family violence. Boston, MA: Massachusetts Advocates for Children.

Cook, A., Spinazzola, J., Ford, J., Lanktree, C., Blaustein, M., Cloitre, M., \& Van der 
Kolk, B. (2005). Complex trauma. Psychiatric Annals, 35(5), 390-398.

Creswell, J.W. (2014). Research design: Qualitative, quantitative, and mixed methods approaches (4th ed.). Thousand Oaks, CA: SAGE.

Creswell, J. (2013). Qualitative inquiry and research design: Five different approaches. Thousand Oaks, CA: SAGE.

Crotty, M. (1998). The foundations of social research: Meaning and perspective in the research process. Thousand Oaks, CA: SAGE.

Crouch, J. L., Hanson, R. F., Saunders, B. E., Kilpatrick, D. G., \& Resnick, H. S. (2000). Income, race/ethnicity, and exposure to violence in youth: Results from the national survey of adolescents. Journal of Community Psychology, 28(6), 625641.

Cutcliffe, J. R., \& McKenna, H. P. (1999). Establishing the credibility of qualitative research findings: The plot thickens. Journal of Advanced Nursing, 30(2), 374380.

Davies, D. (2004). Child development: A practitioner's guide. (2nd ed.). New York, NY: Guilford.

Darling-Hammond, L. (2000). Teacher quality and student achievement. Education Policy Analysis Archives, 8(1), 1-44.

Darling-Hammond, L. (2006). Constructing 21st-century teacher education. Journal of Teacher Education, 57(3), 300-314.

DePrince, A. P., Weinzierl, K. M., \& Combs, M. D. (2009). Executive function performance and trauma exposure in a community sample of children. Child Abuse \& Neglect, 33(6), 353-361. 
Devilly, G. J., Wright, R., \& Varker, T. (2009). Vicarious trauma, secondary traumatic stress or simply burnout? Effect of trauma therapy on mental health professionals. Australian and New Zealand Journal of Psychiatry, 43(4), 373-385.

Dominguez-Gomez, E., \& Rutledge, D. N. (2009). Prevalence of secondary traumatic stress among emergency nurses. Journal of Emergency Nursing, 35(3), 199-204.

Dutton, M. A., \& Rubinstein, F. L. (1995). Working with people with PTSD: Research implications. In Figley C.R. (Ed.), Compassion fatigue: Coping with secondary traumatic stress disorder in those who treat the traumatized, (pp. 82-100).

Edwards, R., \& Holland, J. (2013). What is qualitative interviewing? London: Bloomsbury.

Epstein, S. (1985). The implications of cognitive-experiential self-theory for research in social psychology and personality. Journal for the Theory of Social Behaviour, 15(3), 283-310.

Etikan, I., Musa, S. A., \& Alkassim, R. S. (2016). Comparison of convenience sampling and purposive sampling. American Journal of Theoretical and Applied Statistics, 5(1), 1-4.

Etzion, D. (1984). Moderating effect of social support on the stress-burnout relationship. Journal of Applied Psychology, 69(4), 615 -622.

Evans, G. W. (2004). The environment of childhood poverty. American Psychologist, 59(2), 77-92. http://dx.doi.org.echo.louisville.edu/10.1037/0003066X.59.2.77

Felitti, V. J., Anda, R. F., Nordenberg, D., Williamson, D. F., Spitz, A. M., Edwards, V., \& Marks, J. S. (1998). Relationship of childhood abuse and household 
dysfunction to many of the leading causes of death in adults: The adverse childhood experiences (ACE) study. American Journal of Preventive Medicine, 14(4), 245-258.

Figley, C. R. (Ed.) (1995). Compassion fatigue: Coping with secondary traumatic stress disorder. New York: Brunner/Mazel.

Farmer, E. M., Burns, B. J., Phillips, S. D., Angold, A., \& Costello, E. J. (2003). Pathways into and through mental health services for children and adolescents. Psychiatric Services, 54(1), 60-66.

Freudenberger H. \& Robbins A. (1979). The hazards of being a psychoanalyst. Psychoanalyst Review, 66(2) 275-296. Retrieved from http:www.ncbi.nlm.nih.gov/pubmed061317.

Furrer, C., \& Skinner, E. (2003). Sense of relatedness as a factor in children's academic engagement and performance. Journal of Educational Psychology, 95(1), 148162.

Geller, J. A., Madsen, L. H., \& Ohrenstein, L. (2004). Secondary trauma: A team approach. Clinical Social Work Journal, 32(4), 415-430.

Glesne, C. (2016). Becoming qualitative researchers: An introduction. London, England: Pearson.

Golafshani, N. (2003). Understanding reliability and validity in qualitative research. The Qualitative Report, 8(4), 597-606.

Gray, L. \& Taie, S. (2015). Public school teacher attrition and mobility in the first five years: Results from the first through fifth waves of the 2007-08 beginning teacher longitudinal study. (NCES 2015-337). U.S. Department of Education. 
Washington, DC: National Center for Education Statistics.

Hakanen, J. J., Bakker, A. B., \& Schaufeli, W. B. (2006). Burnout and work engagement among teachers. Journal of School Psychology, 43(6), 495-513.

Hanushek, E. A., Kain, J. F., \& Rivkin, S. G. (2004). Why public schools lose teachers. Journal of Human Resources, 39(2), 326-354.

Hoagwood, K., Burns, B. J., Kiser, L., Ringeisen, H., \& Schoenwald, S. K. (2001).

Evidence-based practice in child and adolescent mental health services. Psychiatric Services, 52(9), 1179-1189.

Helm, H. M. (n.d.). Managing vicarious trauma and compassion fatigue. Retrieved from: https://www.researchgate.net/publication/265361070_Managing_Vicarious_Trau ma_and_Compassion_Fatigue_Defining_Vicarious_Trauma_and_Compassion_F atigue

Herman, J. L. (1992). A practical guide to alternative assessment. Alexandria, VA: Association for Supervision and Curriculum Development.

Hill, A. C. (2011). The cost of caring: An investigation in the effects of teaching traumatized children in urban settings (No. 3465009) [Doctoral dissertation, University of Massachusetts Amherst]. ProQuest Dissertations and Theses database.

Hoffman, S., Palladino, J. M., \& Barnett, J. (2007). Compassion fatigue as a theoretical framework to help understand burnout among special education teachers. Journal of Ethnographic and Qualitative Research, 2, 15-22.

Holt, S., Buckley, H., \& Whelan, S. (2008). The impact of exposure to domestic violence on children and young people: A review of the literature. Child Abuse \& 
Neglect, 32(8), 797-810.

Hopson, L. M., \& Lee, E. (2011). Mitigating the effect of family poverty on academic and behavioral outcomes: The role of school climate in middle and high school. Children and Youth Services Review, 33(11), 2221-2229.

Husserl, E. (1970). Logical Investigations, (J.N. Findlay, Trans.)., London: International Library of Philosophy and Scientific Method.

Hurt, H., Malmud, E., Brodsky, N.L., Giannetta, J. (2001). Exposure to violence: Psychological and academic correlates in child witnesses. Archives of Pediatrics $\&$ Adolescent Medicine, 155, 1351-1356.

Hydon, S., Wong, M., Langley, A. K., Stein, B. D., \& Kataoka, S. H. (2015). Preventing secondary traumatic stress in educators. Child and Adolescent Psychiatric Clinics of North America, 24(2), 319-333.

Ingersoll, R. M,. \& Smith, T. M. (2003). The wrong solution to the teacher shortage. Educational Leadership, 60(8), 30-33.

Jankoski, J. A. (2010). Is vicarious trauma the culprit? A study of child welfare professionals. Child Welfare, 89(6), 105-120.

Jensen, E. (2009). Teaching with poverty in mind: What being poor does to kids' brains and what schools can do about it. Alexandria, VA: ASCD.

Johnson, S.M., Kardos, S.M., Kauffman, D., Liu, E., \& Donaldson, M.L. (2004). The support gap: New teachers' early experiences in high-income and low-income schools. Education Policy Analysis Archives, 12(61) 1-24.

Jones, B., \& Nichols, E. (2013). Cultural competence in America's schools. Charlotte, NC: Information Age Publishing, Inc. 
Kaiser, K. (2009). Protecting respondent confidentiality in qualitative research. Qualitative Health Research, 19(11), 1632-1641.

Kelly, S. (2004). An event history analysis of teacher attrition: Salary, teacher tracking, and socially disadvantaged schools. Journal of Experimental Education, 72(3), 195-220.

Kena, G., Hussar, W., McFarland, J., de Brey, C., Musu-Gillette, L., Wang, X., \& Barmer, A. (2016). The Condition of Education 2016. (NCES 2017144).. National Center for Education Statistics.

Killian, K. (2008). Helping till it hurts? A multimethod study of compassion fatigue, burnout, and self-care in clinicians working with trauma survivors. Traumatology, 14(2), 32-44.

Kiser, L. J. (2007). Protecting children from the dangers of urban poverty. Clinical Psychology Review, 27(2), 211-225.

Ko, S. J., Ford, J. D., Kassam-Adams, N., Berkowitz, S. J., Wilson, C., Wong, M., Brymer, M., \& Layne, C. M. (2008). Creating trauma-informed systems: child welfare, education, first responders, health care, juvenile justice. Professional Psychology: Research and Practice, 39(4), 396-404.

Lankford, H., Loeb, S., \& Wyckoff, J. (2002). Teacher sorting and the plight of urban schools: A descriptive analysis. Educational Evaluation and Policy Analysis, 24(1), 37-62.

Lansford, J. E., Dodge, K. A., Pettit, G. S., Bates, J. E., Crozier, J., \& Kaplow, J. (2002). A 12-year prospective study of the long-term effects of early child physical maltreatment on psychological, behavioral, and academic problems in 
adolescence. Archives of Pediatrics \& Adolescent Medicine, 156(8), 824-830.

Lyons-Ruth, K., Alpern, L., \& Repacholi, B. (1993). Disorganized infant attachment classification and maternal psychosocial problems as predictors of hostileaggressive behavior in the preschool classroom. Child Development, 64(2), 572585.

Margolin, G., \& Gordis, E. B. (2000). The effects of family and community violence on children. Annual Review of Psychology, 51, 445-479.

Maslach, C., Jackson, S. E., \& Leiter, M. P. (1996). Maslach burnout inventory manual (3rd Ed.). Palo Alto, CA: Consulting Psychologists Press.

Maslach, C., \& Leiter, M. P. (2016). Understanding the burnout experience: recent research and its implications for psychiatry. World Psychiatry, 15(2), 103-111.

Maslach, C., Schaufeli, W. B., \& Leiter, M. P. (2001). Job burnout. Annual review of psychology, 52(1), 397-422.

McCann, I. L., \& Pearlman, L. A. (1990). Vicarious traumatization: A framework for understanding the psychological effects of working with victims. Journal of Traumatic Stress, 3(1), 131-149.

McCloskey, L. A., \& Walker, M. (2000). Posttraumatic stress in children exposed to family violence and single-event trauma. Journal of the American Academy of Child and Adolescent Psychiatry, 39(1), 108-115.

McFarland, J., Hussar, B., de Brey, C., Snyder, T., Wang, X., Wilkinson-Flicker, S., Gebrekristos, S., Zhang, J., Rathbun, A., Barmer, A., Bullock Mann, F., \& Hinz, S. (2017). The Condition of Education 2017 (NCES 2017- 144). U.S. Department of Education. Washington, DC: National Center for Education Statistics. 
McGarrigle, T., \& Walsh, C. A. (2011). Mindfulness, self-care, and wellness in social work: Effects of contemplative training. Journal of Religion \& Spirituality in Social Work: Social Thought, 30(3), 212-233.

McManus, I. C., Winder, B. C., \& Gordon, D. (2002). The causal links between stress and burnout in a longitudinal study of UK doctors. The Lancet, 359(9323), 20892090.

Moustakas, C. (1994). Phenomenological research methods. Thousand Oaks, CA:

SAGE.

National Center for Mental Health Promotion and Youth Violence Prevention. (2012). Childhood trauma and its effect on healthy development.

National Child Traumatic Stress, Network, Physical Abuse Collaborative Group. (2009). Child physical abuse fact sheet. Los Angeles, CA \& Durham, NC. https://www.nctsn.org/sites/default/files/resources/child_physical_abuse_fact_she et.pdf

National Research Council and Institute of Medicine. (2009). Preventing mental, emotional, and behavioral disorders among young people: Progress and possibilities. Washington, DC: The National Academic Press.

Olsen, B. (2008). How reasons for entry into the profession illuminate teacher identity development. Teacher Education Quarterly, 35(3) 23-40.

Orem, D. E., Taylor, S. G., \& Renpenning, K. M. (2001). Nursing concepts of practices (6th ed.). St. Louis: Mosby.

Orfield, G., Losen, D., Wald, J., \& Swanson, C. (2004). Losing our future: How minority youth are being left behind by the graduation rate crisis, Cambridge, MA: The 
Civil Rights Project at Harvard University. Contributors: Urban Institute, Advocates for Children of New York, and The Civil Society Institute.

Osterman, K. F. (2000). Students' need for belonging in the school community. Review of Educational Research, 70(3), 323-367.

Pearlman, L. A., \& Mac Ian, P.S. (1995). Vicarious traumatization: An empirical study of the effects of trauma work on trauma therapists. Professional Psychology: Research and Practice, 26(6), 558-565.

Pearlman, L. A., \& Saakvitne, K. W. (1995). Trauma and the therapist: Countertransference and vicarious traumatization in psychotherapy with incest survivors. New York: WW Norton \& Co.

Pines, A., \& Maslach, C. (1978). Characteristics of staff burnout in mental health settings. Psychiatric Services, 29(4), 233-237.

Porter, E, \& Cohen, M. (2013). Phenomenology. In A. Trainor \& E. Graue (Eds.), Reviewing qualitative research in the social sciences (pp. 180-196). New York: Routledge.

Raver, C., Gershoff, E., \& Aber, J. (2007). Testing equivalence of mediating models of income, parenting, and school readiness for white, black, and Hispanic children in a national sample. Child Development, 78(1), 70-95.

Ringel, S., \& Brandell, J. R. (Eds.). (2011). Trauma: Contemporary directions in theory, practice, and research. Thousand Oaks, CA: SAGE.

Rivkin, S. G., Hanushek, E. A., \& Kain, J. F. (2005). Teachers, schools, and academic achievement. Econometrics, 73, 417-458.

Saakvitne, K. W., Pearlman, L. A., \& Abrahamson, D. J. (1996). Transforming the pain: 
A workbook on vicarious traumatization. New York: WW Norton.

Salloum, A., Kondrat, D. C., Johnco, C., \& Olson, K. R. (2015). The role of self-care on compassion satisfaction, burnout and secondary trauma among child welfare workers. Children and Youth Services Review, 49, 54-61.

Schaufeli, W. B., Leiter, M. P., \& Maslach, C. (2009). Burnout: 35 years of research and practice. Career Development International, 14(3), 204-220.

Schunk, D. H. (2012). Learning theories an educational perspective sixth edition. Boston: Pearson.

Shonkoff, J. P., \& Garner, A. S., .(2012). Committee on Psychosocial Aspects of Child and Family Health, Committee on Early Childhood Adoption and Dependent Care, \& Section on Developmental and Behavioral Pediatrics. The lifelong effects of early childhood adversity and toxic stress. 232- 246.

http://dx.doi.org.echo.louisville.edu/10.1542/peds.2011-2663

Skovholt, T. M., \& Trotter-Mathison, M. (2016). The resilient practitioner: Burnout and compassion fatigue prevention and self-care strategies for the helping professions. London: Routledge.

Sprang, G., Craig, C., \& Clark, J. (2011). Secondary traumatic stress and burnout in child welfare workers: a comparative analysis of occupational distress across professional groups. Child Welfare, 90(6) 149-168.

Sprang, G., Clark, J. J., \& Whitt-Woosley, A. (2007). Compassion fatigue, compassion satisfaction, and burnout: Factors impacting a professional's quality of life. Journal of Loss and Trauma, 12(3), 259-280.

Stoeber, J., \& Rennert, D. (2008). Perfectionism in school teachers: Relations with stress 
appraisals, coping styles, and burnout. Anxiety, Stress, and Coping, 21(1), 37-53.

Streeck-Fischer, A., \& van der Kolk, B. A. (2000). Down will come baby, cradle and all: Diagnostic and therapeutic implications of chronic trauma on child development. Australian and New Zealand Journal of Psychiatry, 34(6), 903-918.

Strömberg A, Jaarsma, T., \& Riegel, B. (2012). Self-care: who cares? European Journal of Cardiovascular Nursing: Journal of the Working Group on Cardiovascular Nursing of the European Society of Cardiology, 11(2), 133-4. https://doi.org/10.1177/1474515111429660

Swathi, V., \& Reddy, M. S. (2016). Implications of stress on quality of work life among teachers: An empirical study. IPE Journal of Management, 6(1).

Taie, S., \& Goldring, R. (2017). Characteristics of public elementary and secondary school teachers in the united states: Results from the 2015-16 national teacher and principal survey. First Look. (NCES 2017-072). National Center for Education Statistics.

Tuohy, D., Cooney, A., Dowling, M., Murphy, K., \& Sixsmith, J., (2013). An overview of interpretive phenomenology as a research methodology. Nurse Researcher, 20(6), 17-20.

U.S. Department of Health \& Human Services, Administration for Children and Families, Administration on Children, Youth and Families, Children's Bureau. (2018). Child maltreatment 2016. Retrieved (include date) from https://www.acf.hhs.gov/cb/research-data-technology/statistics-research/childmaltreatment.

Valent, P. (1995). Survival strategies: A framework for understanding secondary 
traumatic stress and coping in helpers. In C. R. Figley (Ed.), Compassion fatigue (pp. 21-50). New York: Brunner/ Mazel.

VanBergeijk, E., \& Sarmiento, T. (2006). The consequences of reporting child maltreatment: Are school personnel at risk for secondary traumatic stress? Brief Treatment and Crisis Intervention, 6(1), 79-98.

Van der Kolk, B. A. (2003). The neurobiology of childhood trauma and abuse. Child and Adolescent Psychiatric Clinics of North America, 12(2), 293-317.

Van Manen, M. (1990). Researching lived experience: Human science for an active sensitive pedagogy. Albany: State University of New York Press.

Van Manen, M. (2007). Phenomenology of practice. Phenomenology \& Practice, 1(1), 11-30.

Vygotsky, L. S. (1998). The problem of age. The collected works of LS Vygotsky, 5, 187206.

Wadsworth, M. E., Raviv, T., Reinhard, C., Wolff, B., Decarlo Santiago, D., \& Einhorn, L. (2008). An indirect effects model of the association between poverty and child functioning: The role of children's poverty-related stress. Journal of Loss and Trauma, 13, 156-185.

Weber, D. A., \& Reynolds, C. R. (2004). Clinical perspectives on neurobiological effects of psychological trauma. Neuropsychology Review, 14(2), 115-129.

Wellings, K., Branigan. P., \& Mitchell, K. (2000). Discomfort, discord and discontinuity, as data: using focus groups to research sensitive topics. Culture, Health \& Sexuality, 2(3), 255-267. https://doiorg.echo.louisville.edu/10.1080/136910500422241 
Wilcox, P. (2011, February 28). An interview with Dr. Laurie Pearlman on Vicarious Traumatization [Online resource forum]. Retrieved (include date) from https://traumaticstressinstitute.org/interview-with-dr-laurie-pearlman-onvicarious-traumatization/

Yassen, J. (1995). Preventing secondary traumatic stress disorder. In C. R. Figley (Ed.), Compassion fatigue (pp. 178-208). New York: Brunner/Mazel.

Yehuda, R., Halligan, S. L., \& Grossman, R. (2001). Childhood trauma and risk for PTSD: Relationship to intergenerational effects of trauma, parental PTSD, and cortisol excretion. Development and Psychopathology, 13, 733-753.

Zyromski, B. (2007). African American and Latino youth and post-traumatic stress syndrome: Effects on school violence and interventions for school counselors. Journal of School Violence, 6(1), 121-137. 


\section{APPENDICES}

\section{APPENDIX A}

\section{RECRUITMENT LETTER}

Dear Educator,

My name is Terri Davenport, and I am conducting a study for my doctoral research at the University of Louisville, College of Education and Human Development. I am interested in examining the impact on educators who work with students who experience trauma. The findings of this study will be used in my dissertation and may be used in future publications and presentations.

I am interested in your work with students who live in challenging social environments with ongoing stressors, such as family (physical abuse, sexual assault, or neglect), community violence, bereavement and loss issues, parental mental health and substance abuse, poverty, or homelessness. I am specifically interested in learning about how teaching traumatized students influences you both professionally and personally. You were invited to participate in this study because you work in a Title I school with a high concentration of students who qualify for free and reduced meals. The criteria to be eligible to participate in this study are as follows: 1) serve as an elementary educator who has primary responsibility for teaching one class; 2) you must work in a Title I school with a high concentration of students that qualify for free and reduced meals; and 3) selfidentify as having experienced secondary trauma. 
This study will explore specifically secondary trauma among educators.

Secondary trauma is defined as a specific acute trauma of hearing about the trauma of another. Common symptoms that may result from secondary trauma include anger, chronic exhaustion and fatigue, fear, hopelessness, intrusive thoughts, and poor concentration. These symptoms can carry beyond the workday to the educator's personal life as well. Participants for this study will need to self-identify as having experienced secondary trauma. You will be asked probing questions about that exposure, including how you learned of your students' experiences and the way you managed and coped with the acquired knowledge.

If you choose to become a participant, you will be asked to participate in a 60 - to 90-minute, face-to-face interview with me. We can schedule a convenient date, time, and location for the interview. With your permission, the interview will be audio-visually recorded; all recordings will be safeguarded using password-protected devices. I will protect both your identity and that of your school by applying pseudonyms and disguising identifying information. You should understand, however, that I may quote directly from our interviews but will not use your name in any part of the study, and any identifying information will be masked. If you are interested, upon request, I will provide you with an executive summary of the findings from this study.

I appreciate your consideration for participation in this important study. If you are interested in participating, please contact me at tldave01@louisville.com.

Sincerely, Terri Davenport 


\section{APPENDIX B}

Subject Informed Consent Document

A Qualitative Look at Secondary Trauma Through the Lived Experiences of Elementary

Teachers

Primary Investigator name \& address: Mary Brydon-Miller, College of Education and Human Development University of Louisville, 1905 S. First Street, Louisville, KY 40292

Sub-Investigator(s) name \& address: Terri Davenport, 900 S Floyd Street Louisville, KY 40203

Sites where the study is to be conducted:

Phone number for subjects to call for questions: Terri Davenport,

\section{Introduction and Background Information}

You are invited to participate in a research study. This study is being conducted by Terri Davenport, a Doctoral Candidate for Educational Leadership and Organizational Development under the guidance of Dr. Mary Brydon-Miller. This study is authorized by and the University of Louisville, institutional review boards. This study will take place at an agreed-upon location, such as a private room at the local library. Approximately 10 educators will be invited to participate.

\section{Purpose}

The purpose of this qualitative study is to explore the lived experiences of elementary teachers who have experienced secondary trauma while working with students who have exposure to trauma - how educators are impacted by the emotional pain of their students, and to gain insight on coping mechanisms they used to manage the experiences.

\section{Procedures}

You are being asked to participate in individual interviews to share experiences of working with students who have been exposed to trauma. As a participant in this research study, you will be audiotaped during the interviews by me in order to capture your responses effectively.

\section{Potential Risks}

As a participant in this study, there may be some discomfort from answering personal questions about your experiences. Participants may opt not to answer a question if it makes them feel uncomfortable.

\section{Benefits}

This study provides voice for participants to share their experiences of working with students who have experienced trauma.The findings can bring awareness of the phenomenon and can bring about opportunities to protect the well-being of other educators including the participants.

\section{Payment}


You will not be compensated for your time or inconvenience.

\section{Affiliated Sites}

Study activities will take place at various locations at the preference of the participant.

Potential sites include a private room at a library, district office space, or school location.

\section{Confidentiality}

Total privacy cannot be guaranteed. We will protect your privacy to the extent permitted by law. If the results from this study are published, your name will not be made public. Your information may be shared with the following:

- The University of Louisville Institutional Review Board

- Human Subjects Protection Program Office, Privacy Office, others involved in research administration and compliance at the University,

- and other contacted by the University for ensuring human subjects safety or research compliance.

All data collected pertaining to this research study will be kept confidential.

\section{Security}

Your information will be kept private by its storage in a secure area and passwordprotected computer in the home of the co-investigator.

\section{Voluntary Participation}

Taking part in this study is voluntary. You may choose not to take part at all. If you choose to become a participant, you may drop out at any time. There is no cost to participate and no compensation for participating.

\section{Contact Persons}

If you have any questions, concerns, or complaints about the research study, please contact Terri Davenport at—; tldave01@louisville.edu or Dr. Mary Brydon-Miller at (502) 852-6887.; mary.brydon-miller@louisville.edu.

\section{Research Subject's Rights}

If you have questions about your rights as a research subject, you can contact the Human Subjects Protection Program Office at (502) 852-5188. You may discuss any questions about your rights as a research subject, in private, with a member of the Institutional Review Board (IRB). You may also call this number if you have other questions about the research, and you cannot reach the study doctor, or want to talk to someone else. The IRB is an independent committee made up of people from the university community, staff of the institutions, as well as people from the community not connected with these institutions. The IRB has approved the participation of human subjects in this research study.

\section{Concerns and Complaints}

If you have any concerns or complaints about the research or research staff and do not wish to give your name, you may call the toll free number at 1-877-852-1167. This is a 24-hour hot line answered by people who are not employed at the University of 
Louisville.

\section{Acknowledgement and Signatures}

This informed consent is not a contract. This document explains what will happen during the study if you choose to participate. Your signature indicates that this study has been explained to you, that your questions have been answered, and that you agree to take part in this study. You are not giving up any legal rights to which you are entitled by signing this informed consent document. You will be given a copy of this consent form to keep for your records.

(Please Print)

Subject Name

Subject Signature

Date signed

Investigator Name

Investigator

Signature

Date signed

List of Investigators:

Dr. Mary Brydon-Miller

Terri Davenport
Phone Numbers:

(502) 852-6887 


\section{APPENDIX C}

\section{THE IMPACT OF TRAUMATIZED STUDENTS ON EDUCATORS: INTERVIEW}

\section{QUESTIONS}

Interviews will be conducted using an open-ended, semi-structured format. The following questions will guide the interview, and the questions will be adapted as necessary to expand on the participant responses and to increase the depth of the interview content.

\section{$\underline{\text { General Questions }}$}

Interview Q 1 How long have you been an educator?

Interview Q 2 How long at (name of school)?

Interview Q 3 Why did you choose to be an educator?

Acquiring Information about Traumatized Students

Interview Q 4 How do you learn about your students' experience with trauma?

Interview Q 5 Please share a specific example of an experience you had with a particular traumatized student.

Interview Q 6 How did you process the experience both during and after?

$\underline{\text { Personal Impact of Working with Traumatized Students }}$

Interview Q 7 Please describe the personal experiences you have had as a result of hearing traumatic stories from your students.

Interview Q 8 What special challenges have you encountered in working with students who have experienced trauma?

Interview Q 9 Do you believe that working with traumatized children has influenced your ability to connect with family and friends?

If so, in what ways?

\section{Coping Strategies}


Interview Q 10 Who do you talk with to help you address the personal issues that come up for you while working with students who have experienced trauma?

Interview Q 11 How do you take care of yourself in the demanding profession of teaching?

Concluding Questions

Interview Q 12 Is there anything else (experiences, memories, scenarios with traumatized children) that you would like to share?

Interview Q 13 Do you have any additional questions, comments, and/or concerns? Interview Q 14 Please describe your thoughts and feelings, and/or what stands out about this interview? 


\section{APPENDIX D}

Interview Protocol Matrix

\begin{tabular}{|l|c|c|c|c|c|}
\hline & $\begin{array}{c}\text { Background } \\
\text { Information }\end{array}$ & $\begin{array}{c}\text { Research } \\
\text { Question 1 }\end{array}$ & $\begin{array}{c}\text { Research } \\
\text { Question 2 }\end{array}$ & $\begin{array}{c}\text { Research } \\
\text { Question 3 }\end{array}$ & $\begin{array}{c}\text { Concluding } \\
\text { Questions }\end{array}$ \\
\hline Interview Q 1 & $\mathrm{X}$ & & & & \\
\hline Interview Q 2 & $\mathrm{X}$ & & & & \\
\hline Interview Q 3 & $\mathrm{X}$ & & & & \\
\hline Interview Q 4 & & $\mathrm{X}$ & & & \\
\hline Interview Q 5 & & $\mathrm{X}$ & & & \\
\hline Interview Q 6 & & $\mathrm{X}$ & & & \\
\hline Interview Q 7 & & & $\mathrm{X}$ & & \\
\hline Interview Q 8 & & & $\mathrm{X}$ & & \\
\hline Interview Q 9 & & & $\mathrm{X}$ & & \\
\hline Interview Q 10 & & & & $\mathrm{X}$ & \\
\hline Interview Q 11 & & & & & \\
\hline Interview Q 12 & $\mathrm{X}$ & & & & \\
\hline Interview Q 13 & & & & & \\
\hline
\end{tabular}




\section{APPENDIX E}

\section{REFERRAL LIST FOR PARTICIPANTS}

As a participant, you will be asked to examine and reflect on your experiences of working with traumatized children. This study may require you to disclose sensitive personal information, which may bring up powerful emotions. Due to the potential risk of emotional distress associated with participation in this study, I have included the following local mental health referral resources for you to use at your discretion.

\section{Centerstone}

(502) 589-1100

$101 \mathrm{~W}$. Muhammad Ali Blvd.

Louisville, KY 40202

Centerstone has provided patient-focused, reliable, affordable mental health care for over 149 years. They specialize in mental health and counseling needs for issues including depression and trauma.

\section{Human Development Program}

JCPS Employee Assistance Program

(502) 589-4357

The (EAP) Employee Assistance Program is a benefit provided to employees and household family members. An EAP offers confidential assessment, short-term counseling, crisis intervention and, if needed, referral to other resources in the community. 
CURRICULUM VITAE

Terri Davenport

Tdavenp1@aol.com (502)727-8714

\section{$\underline{\text { EDUCATION }}$}

Doctoral Student, Education Leadership and Organizational Development (2015 - present) University of Louisville, Louisville KY

Superintendent Certification (2014) Eastern Kentucky University, Richmond, KY

Kentucky Principal Certification (2007) University of Louisville, Louisville KY

Education Program Consultant Approval (2005) University of Louisville, Louisville KY

Master of Arts in Educational Leadership (2002) (K-5) - University of Louisville, Louisville, KY

Bachelor of Arts (1997) - University of Louisville, Louisville, KY

\section{PROFESSIONAL EXPERIENCE}

- 2015-Present: Compliance Specialist Early Childhood for Jefferson County Public Schools (JCPS)

- $2014-2015$ District Principal

- 2010 - 2014 Principal at Maupin Elementary \& JCPS

- 2009-2010: Principal Intern, JCPS

- 2005-2009: Instructional Coach, Foster Traditional Academy, JCPS

- 1997-2005: Teacher, Jefferson County Public Schools, JCPS

\section{AWARDS, RECOGNITION, and MEMBERSHIP}

- National Association for the Education of Young Children, 2018, 2019, 2020

- Kentucky Leadership Institute for School Principals, 2013 
- Recognized by Educational Leadership December 2012/January 2013 for Project Based Learning

- Kentucky Colonel, 2009, 2013

- Co-grant writer for installation of Kenwood Elementary Family Resource Center, 1998

- Delta Sigma Theta Sorority, Inc.

- Women Scholars of Color, University of Louisville 